\title{
Top Down or Bottom Up?
}

Evidence From the Longitudinal Development of Global and Domain-Specific Self-Esteem in Adulthood

\author{
Katrin Rentzsch \\ Psychologische Hochschule Berlin \\ Michela Schröder-Abé \\ University of Potsdam
}

in press

Journal of Personality and Social Psychology

(C) 2021, American Psychological Association. This paper is not the copy of record and may not exactly replicate the final, authoritative version of the article. Please do not copy or cite without authors' permission. The final article will be available, upon publication, via its DOI: $10.1037 /$ pspp0000393

\section{Author Note}

Katrin Rentzsch, Personality Psychology and Psychological Assessment, Psychologische Hochschule Berlin; Michela Schröder-Abé, Department of Psychology, University of Potsdam.

The preregistration document is provided at https://osf.io/bukpw/. Open science material including data and code can be accessed at https://osf.io/h4qwt/.

We thank Janis Jung, Thomas Lösch, and Mareike Müller for help with data management and Jane Zagorski for proofreading.

Correspondence concerning this article should be addressed to Katrin Rentzsch, Personality Psychology and Psychological Assessment, Psychologische Hochschule Berlin, Am Köllnischen Park 2, 10179 Berlin, E-Mail: k.rentzsch@phb.de 


\begin{abstract}
Classical theoretical perspectives have implied that either global self-esteem has an impact on domain-specific self-esteem (top-down) or domain-specific self-esteem affects global selfesteem (bottom-up). The goal of the present research was to investigate whether classical topdown and bottom-up approaches could withstand a thorough test. To do so, we applied elaborate analytical methods in a 4-wave longitudinal study across 6 years with preregistered hypotheses and data analyses. We analyzed data from $N=1,417$ German participants $(30.6 \%$ men, median of 12 to 13 years of education) with an average age of 47.0 years $(S D=12.4$, Range 18 to 88$)$ at intake. Analyses using latent variable approaches for modeling intraindividual change provided evidence of top-down effects only. For example, participants with higher global self-esteem exhibited an increase in performance self-esteem but not vice versa. Our results also provided evidence of "vertical" associations between global and domain-specific self-esteem, that is, parallel development within the same time frame. In addition, the analyses revealed high rank order stability and a substantial trait component in global self-esteem and the self-esteem domains. The present findings have important theoretical and practical implications for the stability and development of self-esteem in adulthood and advance the understanding of global and domain-specific self-esteem in personality theory.
\end{abstract}

Keywords: self-esteem, domain-specific, top-down and bottom-up, stability, adulthood 


\section{Top Down or Bottom Up?}

\section{Evidence From the Longitudinal Development of Global and Domain-Specific Self-Esteem in Adulthood}

Self-esteem reflects the positivity of an individual's self-evaluations (Baumeister, 1998; Coopersmith, 1967; Rosenberg, 1965). It is an integral aspect of human functioning (Kernis, 2006; MacDonald \& Leary, 2012) with important ramifications for social interaction and relationships (Krauss et al., 2020; Leary et al., 1995), mental health, and well-being (Orth et al., 2012; Schröder-Abé et al., 2007; Stinson et al., 2008; Tesser \& Martin, 2006).

There is a long research tradition in which self-esteem is conceptualized as a multidimensional construct that encompasses several domains, for example, self-evaluations in the social domain or in the physical domain (see Shavelson et al., 1976, for a review). ${ }^{1}$ At the same time, individuals hold general feelings of self-worth (global self-esteem as "the way people generally feel about themselves [...] a feeling of affection for oneself that is not derived from rational, judgmental processes"; Brown \& Marshall, 2006, p. 4). A long debate has ensued on the direction of influence between general feelings of self-worth and specific self-evaluations.

Classical top-down theories state that global self-esteem has an impact on domain-specific selfesteem (e.g., Brown et al., 2001), whereas classical bottom-up theories state that domain-specific self-esteem influences global self-esteem (e.g., James, 1890). Given the contradictory perspectives on the direction of influence between global and domain-specific self-esteem, the paucity of empirical research on these issues is surprising. Moreover, a search of the previous literature identified a lack of studies on domain-specific self-esteem in adulthood. Thus, research on the development of both global and domain-specific self-esteem in adults is clearly warranted (see Orth et al., 2021).

The goal of the present research was to investigate whether classical top-down and bottom-up perspectives on the mutual influence between global and domain-specific self-esteem 
could withstand a thorough test by applying elaborate analytical methods in a four-wave longitudinal study with preregistered hypotheses and data analyses. In addition, we also examined the stability of these different forms of self-esteem in adulthood.

\section{Top-Down and Bottom-Up Perspectives on Global and Domain-Specific Self-Esteem}

There is a long research tradition in which self-esteem is conceptualized as a multifaceted construct. Multidimensional models, such as the one by Shavelson et al. (1976), have elaborated both on global self-esteem and broad categories of self-esteem, such as academic self-esteem (evaluations of the self with respect to performance and competence in one's occupation, at work, or at school), social self-esteem (evaluations of the self with respect to social skills or being accepted by others), and physical self-esteem (evaluations of one's physical appearance or abilities). These broad categories may be further divided into more specific domains of selfesteem: For example, physical self-esteem can be split into physical appearance self-esteem and physical ability self-esteem (e.g., Fleming \& Courtney, 1984; Shavelson et al., 1976). Although the domains are positively correlated (e.g., Rentzsch et al., in press), self-esteem levels may differ between domains within an individual. Therefore, investigating the domains provides a more differentiated picture of an individual's self-evaluations. For example, it is possible for individuals to positively evaluate themselves in the performance domain ("I feel good at my job") and negatively evaluate themselves in the social domain ("I feel uncomfortable in social interactions").

Proponents of a multidimensional approach have argued that the self-esteem domains show "different patterns of relations with different background variables, outcomes, and experimental manipulations" (Marsh et al., 2006, p. 16). For example, the predictive power of self-esteem is particularly high when self-esteem is measured at the appropriate level of specificity (Marsh, Trautwein et al., 2006; Rentzsch et al., in press). Self-esteem domains may have evolved as specific "sociometers" that not only help keep track of an individual's social 
inclusion (e.g., Leary et al., 1995) but also monitor status or attractiveness relative to competitors or the value or strength of an individual's social groups. Each domain may serve specific adaptive functions by motivating behaviors, such as specific interpersonal strategies to restore social inclusion, avoid conflicts, or strengthen one's group (Kirkpatrick \& Ellis, 2001; Kirkpatrick et al., 2002).

There has been a long debate on the direction of influence between global and domainspecific self-esteem. Different theoretical perspectives imply either that global self-esteem has an impact on domain-specific self-esteem (top-down) or that domain-specific self-esteem affects global self-esteem (bottom-up).

The affective model of self-esteem development (Brown \& Dutton, 1995; Brown et al., 2001) states that global self-esteem develops early in life and is influenced by relationships with primary caregivers and temperamental factors. The theory claims that the feelings of affection for oneself that characterize global self-esteem are not based on evaluations of one's competencies or qualities in specific domains. According to the model, global self-esteem remains relatively stable and influences domain-specific self-evaluations in a way that amplifies or buffers the influence of external feedback on these self-evaluations. For example, when a person encounters negative feedback in the interpersonal domain, their global self-esteem remains unaffected, whereas their domain-specific self-esteem might become more negative, especially if the person's global self-esteem is low. The hypothesis guiding this understanding is that global self-esteem and domain-specific self-esteem are related in a top-down fashion.

By contrast, William James' (1890) historical perspective is diametrically opposed to the top-down approach. According to James, global self-esteem develops from domain-specific selfevaluations. More specifically, James argued that global self-esteem depends on the extent to which a person's success in a specific domain lines up with the value the person attaches to success in this domain. Individuals who feel confident in domains of relevance (e.g., in school or 
at work) should exhibit high global self-esteem. Individuals who experience failure in domains of importance, and thereby form negative domain-specific self-evaluations, should exhibit low global self-esteem. Some theories about the development of self-esteem are guided by these considerations and claim, for example, that feeling adequate in domains of importance and receiving approval from others will result in the development of high global self-esteem (Harter, 2006; Harter et al., 1998).

A similar prediction about the direction of influence between global and domain-specific self-esteem can be derived from a different research tradition that has focused on the structure of multidimensional self-esteem. In their seminal work, Shavelson et al. (1976) stated that global self-esteem is relatively stable, whereas domain-specific self-esteem is less stable. The theory also claims that external feedback or environmental changes may specifically affect domainspecific self-esteem. For example, success or failure in a sports competition might affect selfesteem in the physical domain but would have little direct effect on global self-esteem. Instead, it has been argued that any change in global self-esteem would require considerable changes in domain-specific self-esteem. The hypothesis guiding this understanding is that global self-esteem and domain-specific self-esteem are related in a bottom-up fashion such that the causal flow moves from domain-specific self-esteem to global self-esteem (see also Shavelson \& Bolus, 1982).

The theoretical perspectives put forward by Brown et al. (2001) and Shavelson et al. (1976) make different predictions about the causal flow between global self-esteem and domainspecific self-esteem. Paradoxically, however, they are in agreement regarding the stability of global versus domain-specific self-esteem: Both assume that global self-esteem is more stable than domain-specific self-esteem. ${ }^{2}$ Indeed, empirical research has supported global self-esteem as a relatively stable construct in adulthood (e.g., Chung et al., 2017; Donnellan et al., 2012; Huang, 2010; Orth et al., 2012; Trzesniewski et al., 2003; Wagner et al., 2014). However, 
empirical research on the stability of domain-specific self-esteem in adulthood is scarce (most studies have primarily been conducted in children and adolescents, e.g., Asendorpf \& Van Aken, 1993; Cole et al., 2001; Marsh et al., 1983; Orth et al., 2021; Preckel et al., 2013; Putnick et al., 2020; von Soest et al., 2016). The few existing studies with adults have demonstrated that domain-specific measures of self-esteem have relatively high stability that is mostly comparable to the stability that has been observed for measures of global self-esteem (e.g., Donnellan et al., 2007; Fleming \& Courtney, 1984; Rentzsch \& Schröder-Abé, 2018). These findings are more in line with research that has proposed that domain-specific reflects how people typically perceive themselves in a specific domain (Fleming \& Courtney, 1984; Janis \& Field, 1959).

\section{Previous Empirical Research on Top-Down and Bottom-Up Processes}

The direction of influence between global self-esteem and domain-specific self-esteem (top-down, e.g., Brown \& Dutton, 1995, vs. bottom-up, e.g., Shavelson et al., 1976) has been understudied, especially when it comes to longitudinal studies in adults. Brown et al. (1995, 2001) conducted experimental studies in which they manipulated success or failure in a performance task. These studies demonstrated that global self-esteem affected how participants felt about themselves after they succeeded or failed. For example, participants who were low but not those who were high in global self-esteem exhibited negative self-evaluations after failure. Results were interpreted in terms of a top-down process. A cross-sectional study of high school students showed that global self-esteem was related to domain-specific self-evaluations, particularly in domains judged as important to the self, and the result was interpreted in terms of a bottom-up process (Harter et al., 1998; see also Chan, 1997, for similar results). To the contrary, recent cross-sectional research using methodologically more sound analyses provided no evidence that weighting by the individual importance of domains had an effect on global selfesteem (e.g., Scalas et al., 2013; see also Donnellan et al., 2007 for similar results). This lack of evidence undermines the bottom-up approach by James (1890). 
The few existing longitudinal studies investigating top-down or bottom-up effects have been limited in at least two ways: First, one group of studies focused only on academic and physical self-esteem in adolescent samples (Gogol et al., 2016; Kowalski et al., 2003; Marsh \& Yeung, 1998; Trautwein et al., 2006). Most of these studies investigated retest intervals of 1 to 2 years and did not provide evidence that supported either bottom-up or top-down approaches (Gogol et al., 2016; Kowalski et al., 2003; Marsh \& Yeung, 1998). A study on young adolescents using 4-month retest intervals reported both bottom-up and top-down processes in math and German academic self-esteem (Trautwein et al., 2006). Second, another group of studies investigated multiple domains (e.g., physical, academic, and social self-esteem) but usually modeled only bottom-up effects: A study on adolescents with a 2-year retest interval did not find longitudinal effects by which domain-specific self-esteem predicted global self-esteem (Harris et al., 2018). By contrast, the study by von Soest et al. (2016) on young and older adolescents with time intervals of 7 to 13 years found bottom-up effects, albeit only for physical self-esteem (see also the study by Donnellan et al., 2007, on young adults). The only longitudinal study investigating both top-down and bottom-up effects in adults that we are aware of did not provide support for either top-down or bottom-up effects across 2 years of measurement (Rentzsch \& Schröder-Abé, 2018).

In sum, previous research on top-down and bottom-up effects in self-esteem is rareespecially in adult populations - and has yielded contradictory results. Differences in previous findings may be due to the use of cross-sectional versus longitudinal study designs, a focus on different age groups and retest intervals, and the investigation of either top-down or bottom-up processes only.

Importantly, top-down and bottom-up approaches assume a causal flow between global and domain-specific self-esteem, implying that the level of (global or domain-specific) selfesteem has an effect on changes in (domain-specific or global) self-esteem. For example, a 
person low in global self-esteem who faces persistent negative feedback at work should experience a decrease in performance self-esteem over time when following the top-down approach (e.g., Brown et al., 2001). Moreover, top-down and bottom-up approaches imply that change in (global or domain-specific) self-esteem has an effect on change in (domain-specific or global) self-esteem. For example, a person who experiences a significant decrease in performance self-esteem due to growing failures at work should then also exhibit a significant decrease in global self-esteem when following the bottom-up approach (e.g., Shavelson et al., 1976). Although theoretical perspectives on top-down and bottom-up processes have elaborated on the impact on intraindividual changes in specific self-esteem domains or global self-esteem, the majority of previous empirical studies did not use designs or statistical models that could adequately account for this. For example, most longitudinal studies attempting to model the longitudinal flow between different forms of self-esteem have used latent cross-lagged panel analyses, thereby facing the problem of potentially biased estimates due to the stability of the construct of interest (see Hamaker et al., 2015). Furthermore, the classical theories ignored the possibility that both top-down and bottom-up processes could be at work simultaneously.

In this study, we used a longitudinal design and novel analytical approaches so that we could (a) model top-down and bottom-up processes, (b) analyze intraindividual change in selfesteem and (c) overcome the problems associated with the use of traditional cross-lagged regression analyses.

\section{Integrating Classical Top-Down/Bottom-Up Perspectives on Self-Esteem and Models of Intraindividual Change}

Classical theories on top-down and bottom-up processes imply a causal effect of global self-esteem on domain-specific self-esteem (or vice versa), which means that level or intraindividual changes in global (domain-specific) self-esteem have an effect on intraindividual changes in domain-specific (global) self-esteem. 
In the present study, we modeled top-down and bottom-up processes by using True Intraindividual Change models (TICMs; Steyer et al., 1997). In these models, change is measured directly through latent difference variables. Latent difference variables represent individual differences in true intraindividual change over time corrected for random measurement error (Steyer et al., 1997). TICMs model true change directly, so there is no need to impose assumptions about the pattern of change as in, for example, growth curve models (Steyer et al., 1997). We used bivariate TICMs that are suitable for assessing the influence between global self-esteem and domain-specific self-esteem in both directions simultaneously in order to obtain a fuller picture of bottom-up and top-down longitudinal processes (see Figure 1). Unlike, for example, in growth curve modeling, we were therefore able to implement crosslagged effects between change variables at different time intervals to indicate whether a change in global or domain-specific self-esteem predicted subsequent change in domain-specific or global self-esteem. Furthermore, we were able to implement cross-lagged effects between the initial levels and subsequent change to indicate whether global (domain-specific) self-esteem predicted change in domain-specific (global) self-esteem. In addition, TICMs provide a way to quantify the degree of mean-level stability over time.

For a more comprehensive analysis of top-down and bottom-up processes, we additionally used Latent Trait-State-Occasion (TSO; Cole et al., 2005) models in order to disentangle stable trait factors (i.e., stable individual differences over time) from more malleable occasion-specific factors in measures of self-esteem. Change is measured through occasionspecific variables that represent intraindividual deviations of self-esteem at a certain point in time from an individual's habitual self-esteem. For example, a person who just got a promotion should experience a significant deviation from their typical level in performance self-esteem. Extending traditional latent state-trait models, the TSO model additionally includes autoregressive effects between the occasion-specific variables from neighboring time points to 
account for situational effects that carry over from one time point to the next. Modeling autoregressive effects is useful in constructs that become less stable with increasing time intervals (e.g., self-esteem; Prenoveau, 2016). Furthermore, it allowed us to estimate the proportion of variance in self-esteem that could be explained by a stable trait factor and an occasion-specific factor. Again, in order to acknowledge the possibility that top-down and bottom-up processes are simultaneously at work within an individual, we implemented bivariate TSO models (see Figure 2). Cross-lagged effects between the occasion-specific factors of neighboring time points indicate the degree to which occasion-specific deviations in global and domain-specific self-esteem predict occasion-specific deviations in domain-specific and global self-esteem across time, thus modeling how intraindividual change predicts intraindividual change (see Hamaker et al., 2006; Luhmann et al., 2011). Unlike traditional cross-lagged panel models, cross-lagged effects from TSO models represent intraindividual processes that do not face potential biases caused by high construct stability (see Hamaker et al., 2006, for more details). The technical details of both models are presented in the Method section.

In sum, TICMs allow the degree of true intraindividual change to be quantified over time, whereas the TSO model allows the degree of stability and variability in terms of proportions of explained variance to be quantified. Importantly, both allow researchers to investigate the mutual influence between global and domain-specific processes over time, by focusing on either true intraindividual change or occasion-specific intraindividual change.

\section{The Present Study}

Classical theories imply either that global self-esteem has an impact on domain-specific self-esteem (top-down; e.g., Brown \& Dutton, 1995) or that domain-specific self-esteem affects global self-evaluations (bottom-up; e.g., James, 1890; Shavelson et al., 1976). Although these opposing theories still dominate contemporary research and theory construction, there is a dearth of empirical research that has tested these theories, especially in adult populations. Due to the 
limited age range in previous studies on domain-specific self-esteem, it is not yet clear whether the results will generalize to adulthood. Furthermore, previous research has been limited in its use of appropriate longitudinal research methods. We aimed to fill this research gap and derived the following hypotheses (see Preregistration $\rightarrow$ Personality Development and Stability $\rightarrow 3$. Top-down vs. bottom-up at https://osf.io/h4qwt/for the preregistration):

1a) When investigating bottom-up and top-down approaches for assessing the influence between domain-specific and global self-esteem, the level of or change in domain-specific selfesteem will predict change in global self-esteem over time if the data follow the bottom-up approach (Harter et al., 1998; Shavelson et al., 1976). 1b) On the other hand, the level of or change in global self-esteem will predict the change in domain-specific self-esteem over time if the data follow the top-down approach (Brown et al., 2001).

2a) In addition, if the data follow the bottom-up approach, occasion-specific deviations in domain-specific self-esteem will predict occasion-specific deviations in global self-esteem over time, 2b) but if the data follow the top-down approach, occasion-specific deviations in global self-esteem will predict occasion-specific deviations in domain-specific self-esteem over time.

Because classical top-down and bottom-up approaches have been linked with assumptions about the temporary stability of global self-esteem and domain-specific self-esteem, with our study, we additionally examined the stability of these different forms of self-esteem. Because these prior theoretical perspectives did not specify whether they referred to rank-order stability and/or mean-level stability, we considered both types of stability in the current study. In addition, we investigated the proportion of variance in self-esteem measures that could be explained by a stable trait factor versus an occasion-specific factor. ${ }^{3}$

In the present study, a participant pool was contacted in 2-year intervals beginning in 2013 and followed across four waves of measurement, thus spanning a time frame of 6 years. The average age of participants was 47 years at intake, ranging from 18 to 88 years. Participants 
completed the Multidimensional Self-Esteem Scale (MSES; Fleming \& Courtney, 1984; Schütz et al., 2016) at each wave of measurement. Using this instrument allowed us to test the aforementioned classical theoretical perspectives because the MSES includes a measure of global self-esteem and measures of domain-specific self-esteem.

\section{Method}

\section{Ethics Statement}

This study was approved by the ethics committee at the University of Bamberg (title: "Persönlichkeitsentwicklung im Längsschnitt").

\section{Preregistration}

The methods, analyses, and hypotheses in the present study were preregistered (see https://osf.io/h4qwt/). ${ }^{4}$ A detailed overview of all measures at each time point and all scripts and the anonymized data used in the analyses are provided in the open-science framework (https://osf.io/h4qwt/). Analyses that deviate from the preregistered protocol are identified as such in the following.

\section{Participants and Procedure}

Participants were recruited from the general German population through a pool that consisted of potential volunteers for participation in lab research. The link that people needed to follow to sign up to be included in the participant pool was announced in regional and national media outlets. As an incentive, participants received personal feedback on their self-esteem profile after participating in the study. The participant pool was contacted in two-year intervals in 2013 (Time 1), 2015 (Time 2), 2017 (Time 3), and 2019 (Time 4). At each wave, participants who had completed previous waves and new participants were included in the study. ${ }^{5}$ Participants who did not provide an anonymous identification code or who participated multiple times per wave were not considered in the final data set. A detailed overview of demographic data at each wave is provided in Table 1. Overall, the sample consisted primarily of highly 
educated, predominantly female German participants of adult age. Of those participating at Time 1, $n=249$ individuals also participated at Time $2, n=208$ participants attended Time 3 , and $n=$ 209 participated at Time 4. Of those individuals who attended Time 2, $n=221$ participated at Time 3 and $n=220$ attended Time 4 . Of the participants who participated at Time $3, n=258$ also attended Time 4. All participants who took part on at least one measurement occasion were included in the analysis, resulting in an overall sample size of 1,417 participants.

\section{Measure}

To measure self-esteem, we used the Multidimensional Self-Esteem Scale (MSES; Schütz et al., 2016), an instrument that exhibits good reliability and validity in adult samples (Rentzsch et al., 2016). The MSES is the German adaptation of the scale created by Fleming and Courtney (1984). Based on the theoretical model provided by Shavelson et al. (1976) and on a revision of the Feelings of Inadequacy Scale (FIS; Janis \& Field, 1959), the scale by Fleming and Courtney (1984) measures the following five scales: self-regard (which we refer to as "global self-esteem" in the following), social confidence, school abilities, physical appearance, and physical abilities. Because analyses in the study by Fleming and Courtney (1984) resulted in a six-factor solution, with the social factor split into two subscales (i.e., social contact and social criticism), the MSES (Schütz et al., 2016) encompassed the following six subscales: ${ }^{6}$

Global self-esteem (e.g., "Do you have a positive attitude toward yourself?," "How often are you so unhappy with yourself that you wonder if you are a valuable person?’): Describes one's global perceptions of self-worth, independent of any particular domain. High scorers have high general self-acceptance, self-confidence, and positive self-evaluations.

Social contact (e.g., "Do you often feel uncomfortable in your own skin when you meet new people?," "How often do you feel self-conscious?"): Refers to one's social skills in the presence of others. High scorers are comfortable about being in contact with others and are confident in their social skills. 
Social criticism (e.g., "How much do you think other people see you as a loser?," "How often do you think that others might criticize your work?"): Describes one's confidence in being approved of by others. High scorers are confident that they are accepted and positively evaluated by others.

Performance (e.g., "How often do you feel like you've done a really good job after you've completed a job?," "How often are you convinced of your performance at work?"): High scorers are confident that their performances are good and that they exhibit competence in their occupation, job, work, or school.

Physical appearance (e.g., "How often do you wish you were more attractive?," "How convinced are you that you are considered a good-looking person?"): Refers to an evaluation of the appearance of one's body. High scorers evaluate themselves as physically attractive and are satisfied with their body.

Physical ability (e.g., "How nervous do you get when people watch you while doing sports?," “Are you satisfied with your athletic ability?"): Refers to an evaluation of one's abilities with respect to sports and physical coordination. High scorers have confidence in their physical abilities.

Each subscale consists of five to seven items. Responses on the 32 items were made on 7 point rating scales ranging from 1 (not at all) to 7 (very much) for items measuring intensity and from 1 (never) to 7 (very much) for items measuring frequency. Internal consistencies for the subscales are displayed in Supplement S1 (https://osf.io/h4qwt/). 
Table 1

Sample Size and Demographics Across Waves

\begin{tabular}{|c|c|c|c|c|}
\hline Wave & $\begin{array}{l}\text { Time } 1 \\
(2013)\end{array}$ & $\begin{array}{l}\text { Time } 2 \\
(2015)\end{array}$ & $\begin{array}{l}\text { Time } 3 \\
(2017)\end{array}$ & $\begin{array}{l}\text { Time } 4 \\
(2019)\end{array}$ \\
\hline Sample size $n$ & 634 & 523 & 523 & 633 \\
\hline \multicolumn{5}{|l|}{ Age } \\
\hline Mean (SD) & $47.0(12.4)$ & $48.9(13.4)$ & $48.8(13.7)$ & $48.8(14.5)$ \\
\hline Range & $18-88$ & $18-83$ & $19-78$ & $18-81$ \\
\hline \multicolumn{5}{|l|}{ Gender } \\
\hline Male $(\%)$ & $190(30.6 \%)$ & $176(34.1 \%)$ & $177(34.7 \%)$ & $190(31.4 \%)$ \\
\hline Female $(\%)$ & $431(69.4 \%)$ & $340(65.9 \%)$ & $333(65.3 \%)$ & $415(68.6 \%)$ \\
\hline \multicolumn{5}{|l|}{ Education } \\
\hline $\begin{array}{l}\text { lower secondary school } \\
\text { degree }(\sim 9 \text { years of } \\
\text { education })\end{array}$ & $22(3.5 \%)$ & & $13(2.5 \%)$ & $20(3.3 \%)$ \\
\hline $\begin{array}{l}\text { intermediate school degree }(\sim \\
10 \text { years of education) }\end{array}$ & $142(22.5 \%)$ & & $100(19.6 \%)$ & $106(17.5 \%)$ \\
\hline $\begin{array}{l}\text { college of applied sciences } \\
\text { entrance qualification }(\sim 13 \\
\text { years of education })\end{array}$ & $71(11.2 \%)$ & & $56(11.0 \%)$ & $61(10.1 \%)$ \\
\hline $\begin{array}{l}\text { high school degree ( } \sim 12 \text { to } 13 \\
\text { years of education) }\end{array}$ & $120(19.0 \%)$ & & $95(18.6 \%)$ & $123(20.3 \%)$ \\
\hline $\begin{array}{l}\text { college or university degree ( } ~ \\
17 \text { to } 19 \text { years of education) }\end{array}$ & $277(43.8 \%)$ & & $244(47.8 \%)$ & $294(48.6 \%)$ \\
\hline No degree & 0 & & $2(0.4 \%)$ & $1(0.2 \%)$ \\
\hline
\end{tabular}

Note. At Time 1, 636 participants completed the questionnaire. We excluded two participants from the present analyses because they reported that they were underage. At Time 2, demographic measures (except age and gender) had not been assessed.

\section{Analytic Strategy}

In order to test our hypotheses, we ran latent longitudinal analyses. In order to investigate global self-esteem, we established a latent factor model representing the global self-esteem subscale of the MSES. In order to investigate specific domains of self-esteem, we established latent factor models for each of the domain-specific subscales of the MSES (i.e., social contact, social criticism, performance, physical appearance, physical ability). 
All models were estimated with Mplus Version 8.4 (Muthén \& Muthen, 1998-2019), which uses the full information maximum likelihood estimator (see Enders, 2010). As preregistered, model fit was assessed with the $\chi^{2}$-test statistic, Comparative Fit Index (CFI), Root Mean Square Error of Approximation (RMSEA), and Standardized Root Mean Square Residual (SRMR) such that values of the $\mathrm{CFI} \geq .90, \mathrm{RMSEA} \leq .08$, and $\mathrm{SRMR} \leq .11$ are considered to reflect an acceptable fit to the data (Marsh et al., 2005). The Bayesian Information Criterion (BIC) and Tucker-Lewis Index (TLI) are also reported. In accordance with the registration, we used $p<.05$ and $95 \%$ confidence intervals for nondirectional hypotheses and $p<.10$ and $90 \%$ confidence intervals for directional hypotheses.

\section{Measurement Invariance}

Before examining the research questions, every measurement model for each of the measures of self-esteem (i.e., global self-esteem and each of the domains of self-esteem) was tested for invariance across the four time points. For each model, four latent factors were allowed to correlate: (a) the latent self-esteem factor from the first measurement in 2013 (Time 1), (b) the latent factor from the second measurement in 2015 (Time 2), (c) the latent factor from the third measurement in 2017 (Time 3), and (d) the latent factor from the fourth measurement in 2019 (Time 4). As preregistered, we used three manifest parcels as indicators for each latent selfesteem factor on the basis of the balancing technique as recommended by Little et al. (2002, p. 166) and as reported in Rentzsch and Schröder-Abé (2018). All models were tested for configural, weak, strong, and strict factorial invariance (Meredith, 1993). In accordance with Cheung and Rensvold (2002), a value of $\Delta$ CFI smaller than or equal to .01 between nested models was regarded as indicating a nonsignificant decrement in fit between the models. Furthermore, we included correlated residuals to account for the use of the same indicators across time (Bollen \& Curran, 2006).

Results from the invariance testing are displayed in Table 2. Results indicated strict 
invariance for global self-esteem with good fit for the strict invariance model (CFI $=.998$,

RMSEA $=.011$, SRMR $=.031)$. The fit indices revealed only a minimal drop in model fit when comparing the restrictive model with the less constrained models and the configural model. BIC values indicated better fit for the strict invariance model than for the less constrained models. Analyses revealed strict invariance for all other measures of domain-specific self-esteem such that the CFIs for the strict invariance models ranged from .987 to .998 , the RMSEAs ranged from .009 to .026 , and there was only a minimal drop in model fit when constraints were imposed on the models. The following analyses were based on the latent models with strict measurement invariance.

\section{Table 2}

Model Fit Indices From Invariance Testing

\begin{tabular}{lrrrrrrrr}
\hline Measures of Self-Esteem & $\chi^{2}$ & $d f$ & $p$ & BIC & TLI & CFI & RMSEA & SRMR \\
\hline Global Self-Esteem & & & & & & & & \\
$\quad$ (configural invariance) & 33.700 & 30 & .29 & 18815.098 & 0.998 & 0.999 & 0.009 & 0.015 \\
$\quad$ (weak invariance) & 39.324 & 36 & .32 & 18777.185 & 0.999 & 0.999 & 0.008 & 0.025 \\
$\quad$ (strong invariance) & 54.866 & 45 & .15 & 18727.420 & 0.997 & 0.998 & 0.012 & 0.030 \\
$\quad$ (strict invariance) & 63.915 & 54 & .17 & 18671.162 & 0.998 & 0.998 & 0.011 & 0.031 \\
Social Contact & & & & & & & & \\
$\quad$ (configural invariance) & 46.215 & 30 & .03 & 20702.048 & 0.993 & 0.997 & 0.020 & 0.018 \\
(weak invariance) & 52.441 & 36 & .04 & 20664.737 & 0.994 & 0.997 & 0.018 & 0.023 \\
(strong invariance) & 72.782 & 45 & .01 & 20619.771 & 0.993 & 0.995 & 0.021 & 0.031 \\
$\quad$ (strict invariance) & 85.087 & 54 & .00 & 20566.768 & 0.993 & 0.994 & 0.020 & 0.033 \\
Social Criticism & & & & & & & & \\
$\quad$ (configural invariance) & 57.814 & 30 & .00 & 21595.810 & 0.988 & 0.995 & 0.026 & 0.023 \\
(weak invariance) & 69.797 & 36 & .00 & 21564.255 & 0.988 & 0.993 & 0.026 & 0.031 \\
(strong invariance) & 87.933 & 45 & .00 & 21517.084 & 0.988 & 0.992 & 0.026 & 0.037 \\
$\quad$ (strict invariance) & 105.218 & 54 & .00 & 21469.063 & 0.988 & 0.990 & 0.026 & 0.042 \\
Performance & & & & & & & & \\
$\quad$ (configural invariance) & 56.188 & 30 & .00 & 19991.726 & 0.985 & 0.993 & 0.025 & 0.028 \\
(weak invariance) & 70.263 & 36 & .00 & 19962.285 & 0.984 & 0.991 & 0.026 & 0.038 \\
(strong invariance) & 77.703 & 45 & .00 & 19904.449 & 0.988 & 0.992 & 0.023 & 0.041 \\
(strict invariance) & 104.397 & 54 & .00 & 19865.869 & 0.984 & 0.987 & 0.026 & 0.051 \\
Physical Appearance & & & & & & & & \\
(configural invariance) & 48.086 & 30 & .02 & 20538.037 & 0.992 & 0.996 & 0.021 & 0.018 \\
(weak invariance) & 58.145 & 36 & .01 & 20504.580 & 0.992 & 0.996 & 0.021 & 0.029
\end{tabular}




$\begin{array}{lllllllll}\text { (strong invariance) } & 65.017 & 45 & .03 & 20446.177 & 0.994 & 0.996 & 0.018 & 0.032 \\ \text { (strict invariance) } & 77.219 & 54 & .02 & 20393.105 & 0.995 & 0.996 & 0.017 & 0.033\end{array}$

Physical Ability

$\begin{array}{llllllllll}\text { (configural invariance) } & 37.089 & 30 & .17 & 23155.896 & 0.995 & 0.998 & 0.013 & 0.021\end{array}$

$\begin{array}{llllllllll}\text { (weak invariance) } & 38.661 & 36 & .35 & 23113.951 & 0.998 & 0.999 & 0.007 & 0.022\end{array}$

$\begin{array}{lllllllll}\text { (strong invariance) } & 49.995 & 45 & .28 & 23060.010 & 0.998 & 0.998 & 0.009 & 0.025\end{array}$

$\begin{array}{llllllllll}\text { (strict invariance) } & 64.788 & 54 & .15 & 23009.529 & 0.996 & 0.997 & 0.012 & 0.033\end{array}$

Note. BIC $=$ Bayesian Information Criterion, TLI $=$ Tucker-Lewis Index, CFI $=$ Comparative Fit Index, RMSEA = Root Mean Square Error of Approximation, SRMR = Standardized RootMean-Square Residual. $N=1412-1417$ due to missing data.

\section{True Intraindividual Change Models}

In TICMs, intraindividual change is measured directly through latent difference variables (Steyer et al., 1997). One set of analyses included latent difference variables between the latent self-esteem factors of neighboring time points (i.e., Time 2 - Time 1 , Time 3 - Time 2, Time 4 Time 3; neighbor change models). All latent self-esteem factors loaded on an initial latent factor at Time 1. The latent difference factors were each measured by the latent self-esteem factor of the respective time point and of all subsequent time points. All loadings were fixed to one. The intercepts of the reference indicators were set to 0 to identify the latent means. The latent difference factors were allowed to correlate. The intercepts and variances of the latent selfesteem factors were set to zero for purposes of identification. Another set of analyses included latent difference variables between the latent self-esteem factors and the first time point (i.e., Time 2 - Time 1, Time 3 - Time 1, Time 4 - Time 1; baseline change models). These models provided a way to estimate mean-level change across the six years of measurement for each measure of self-esteem separately. Latent mean-level change was assessed as the mean of the latent difference factor. Results on the single neighbor TICMs and elaborate results on the single baseline TICMs are presented in the Supplement S2 (https://osf.io/h4qwt/).

Bivariate True Intraindividual Change Models. To analyze top-down and bottom-up processes, we specified five models that each simultaneously combined two True Intraindividual Change Models (Steyer et al., 1997): one for global self-esteem and one for the respective 
measure of domain-specific self-esteem (see Figure 1 for a schematic representation). Here, we used neighbor change models. The initial latent factors of global self-esteem and domain-specific self-esteem at Time 1 were allowed to correlate with each other. We added a cross-lagged path between the initial level factor of global self-esteem on the latent difference factor of domainspecific self-esteem between Time 2 and Time 1, thus indicating a top-down effect (top-downlevel on change effect). We added a cross-lagged path between the initial level factor of domainspecific self-esteem and the latent difference factor of global self-esteem between Time 2 and Time 1, thus indicating a bottom-up effect (bottom-up - level on change effect). To investigate whether change in global self-esteem at a previous time point predicted change in domainspecific self-esteem at a subsequent time point, we added cross-lagged paths between the respective difference factors of neighboring time points, thus indicating a top-down effect (topdown - change on change effect). In order to investigate whether change in domain-specific selfesteem at a previous time point predicted change in global self-esteem at a subsequent time point, we added cross-lagged paths between the respective difference factors of neighboring time points, thus indicating a bottom-up effect (bottom-up - change on change effect). In addition, autoregressive effects were included, and all change factors were regressed on the respective level of self-esteem at the previous time point. Auto-regressive and cross-lagged paths within measures of self-esteem were constrained to be equal across time points, respectively. ${ }^{7}$ The residuals of the latent difference factors at the same time point were allowed to covary. Covariances between change factor residuals were constrained to be equal across time points. ${ }^{7}$

\section{Figure 1}

Top-Down and Bottom-Up Effects in Bivariate True Intraindividual Change Models 


\section{Global Self-Esteem}

Domain-Specific Self-Esteem

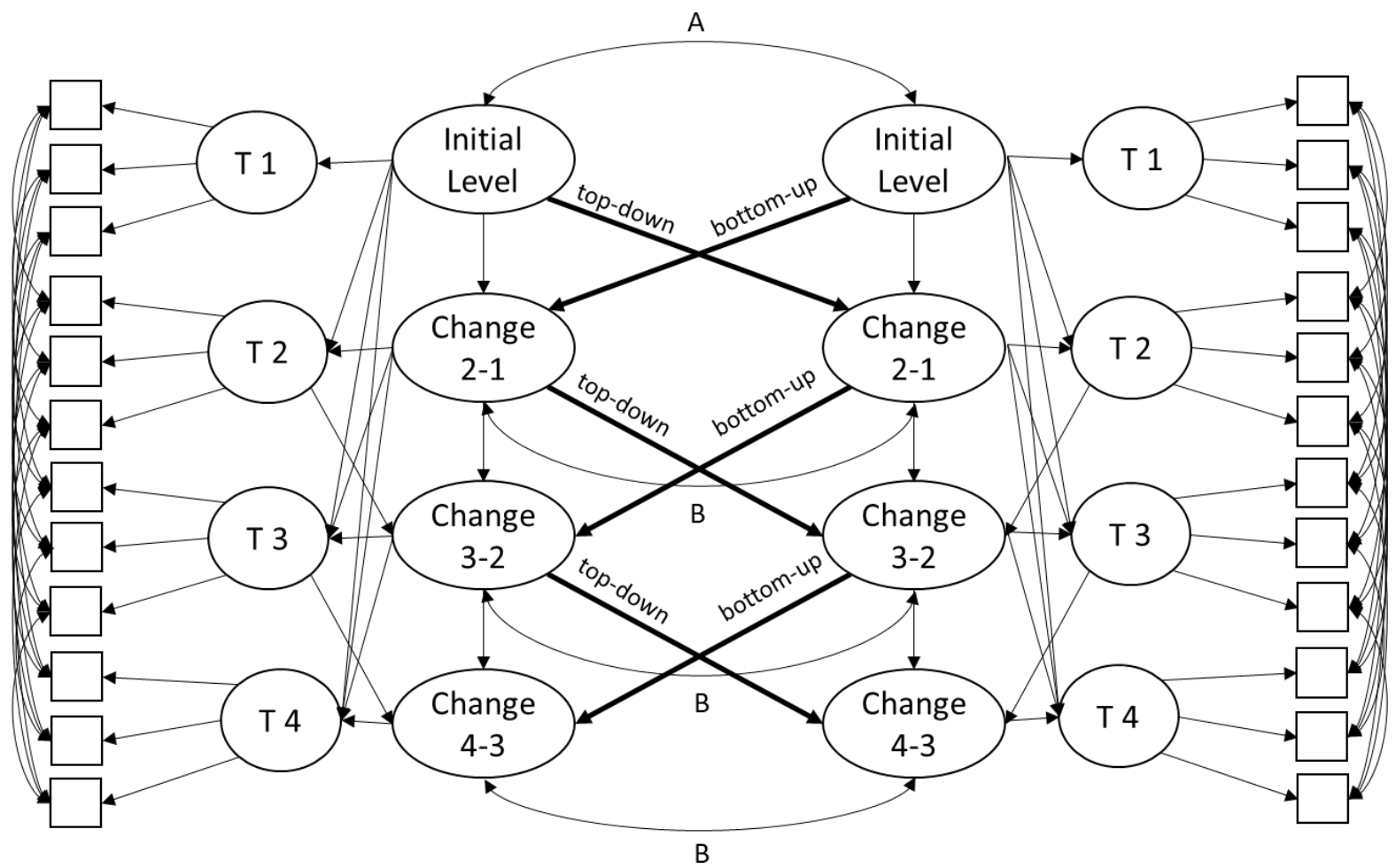

Note. Manifest parcels were used as indicators for each latent self-esteem factor (T1 to T4).

\section{Latent Trait-State-Occasion Models}

In TSO models, the variance of measures is decomposed into stable trait variance and malleable occasion-specific variance (Cole et al., 2005). Accordingly, intraindividual change is measured through occasion-specific deviations from the stable trait. In each single TSO model pertaining to one specific measure of self-esteem, all latent self-esteem factors at every time point loaded on a trait factor that indicated stable trait variance that was free of situational effects. Every self-esteem factor additionally loaded on an occasion-specific factor that indicated occasion-specific deviations of the respective measure of self-esteem from the stable trait. All loadings were fixed to one. The intercepts of the reference indicators were set to zero to identify the latent means. The intercepts of the latent self-esteem factors were set to zero. Because a selfesteem factor at a specific time point was assumed to be completely determined by the trait factor and the occasion-specific factor, the residual variances of the self-esteem factors were set 
to zero. The occasion-specific factor at Time 1 was not allowed to correlate with the trait factor. Each TSO model included autoregressive effects between the occasion-specific factors of neighboring time points indicating the extent to which the measures of self-esteem at adjacent time points were related after accounting for a stable trait factor. The autoregressive effects, residual variances, and factor variances of the occasion-specific factors were constrained to be equal across time intervals (see Prenoveau, 2016).

The TSO model, thus, provides a way to estimate trait variance and occasion-specific variance which indicate the degree of stability and variability of the respective measures of selfesteem. In comparison with related models such as the stable trait, autoregressive trait, and state model (Kenny \& Zautra, 1995), the TSO model has been proven suitable for multiple indicators per time-point which is relevant to correct for random measurement error. Furthermore, previous research has supported a stable estimation of parameters for four-wave longitudinal data when using TSO (Cole et al., 2005).

Bivariate Latent Trait-State-Occasion Models. In order to analyze whether occasionspecific deviations of global self-esteem would predict occasion-specific deviations of domainspecific self-esteem over time (i.e., top-down effects) and whether occasion-specific deviations of domain-specific self-esteem would predict occasions-specific deviations of global self-esteem over time (i.e., bottom-up effects), we specified five models that each simultaneously combined two Latent Trait-State-Occasion Models (Cole et al., 2005): one for global self-esteem and one for the respective measure of domain-specific self-esteem (see Figure 2 for a schematic representation). We added cross-lagged paths between the occasion-specific factors of global self-esteem at a previous time point and the occasion-specific factors of domain-specific selfesteem at a subsequent time point (i.e., top-down effects). We added cross-lagged paths between the occasion-specific factors of domain-specific self-esteem at a previous time point and the occasion-specific factors of global self-esteem at a subsequent time point (i.e., bottom-up 
effects). Auto-regressive and cross-lagged paths within measures of self-esteem were constrained to be equal across time points, respectively. ${ }^{7}$ The initial occasion-specific factors of global selfesteem and domain-specific self-esteem at Time 1 and the residuals of the occasion-specific factors at the same time point were allowed to covary. Covariances between residuals were constrained to be equal across time points. ${ }^{7}$ The trait factors of global and domain-specific selfesteem were allowed to correlate with each other.

\section{Figure 2}

Top-Down and Bottom-Up Effects in Bivariate Trait-State-Occasion Models

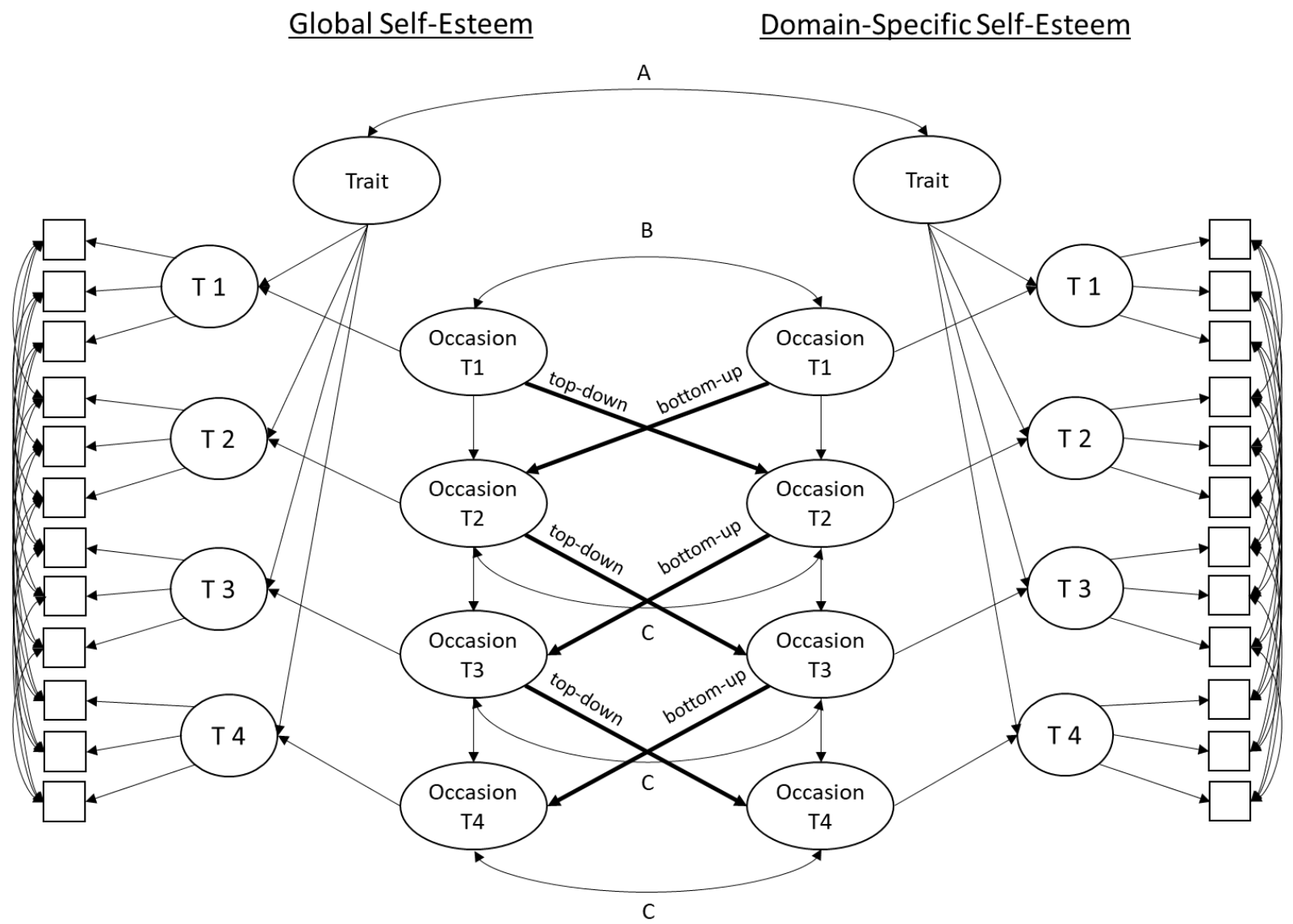

Note. Manifest parcels were used as indicators for each latent self-esteem factor (T1 to T4).

\section{Results}

\section{Preliminary Analyses}

Estimated means, standard deviations, stability coefficients and intercorrelations of all measures of self-esteem across all time points are presented in Tables 3 and 4 . 
Table 3

Estimated Means, Standard Deviations, Rank-Order Stability Coefficients and Mean-Level Change Across Six Years of Measurement

\begin{tabular}{|c|c|c|c|c|c|c|c|c|c|c|c|}
\hline \multirow[t]{2}{*}{ Measures of Self-Esteem } & \multicolumn{2}{|c|}{ Time 1} & \multicolumn{2}{|c|}{ Time 2} & \multicolumn{2}{|c|}{ Time 3} & \multicolumn{2}{|c|}{ Time 4} & $\begin{array}{c}\text { Rank-Order } \\
\text { Stability }\end{array}$ & $\begin{array}{c}\text { Mean-Level } \\
\text { Change }\end{array}$ & $\begin{array}{l}\text { Variance } \\
\text { of Change }\end{array}$ \\
\hline & $M$ & $S D$ & $M$ & $S D$ & $M$ & $S D$ & $M$ & $S D$ & $r$ & $\mathrm{~d}$ & $\mathrm{~S}^{2}$ \\
\hline Global Self-Esteem & 5.15 & 1.06 & 5.24 & 1.03 & 5.25 & 1.08 & 5.28 & 1.06 & .77 & 0.12 & 0.49 \\
\hline Social Contact & 4.84 & 1.43 & 4.98 & 1.40 & 4.98 & 1.43 & 4.96 & 1.41 & .87 & 0.09 & 0.52 \\
\hline Social Criticism & 4.53 & 1.28 & 4.64 & 1.31 & 4.69 & 1.28 & 4.67 & 1.32 & .74 & 0.11 & 0.81 \\
\hline Performance & 4.94 & 0.96 & 4.95 & 0.97 & 4.98 & 0.98 & 4.98 & 0.98 & .77 & 0.04 & 0.42 \\
\hline Physical Appearance & 4.48 & 1.36 & 4.54 & 1.34 & 4.51 & 1.41 & 4.48 & 1.36 & .82 & 0.01 & 0.68 \\
\hline Physical Ability & 4.38 & 0.96 & 4.41 & 0.98 & 4.38 & 1.01 & 4.31 & 1.00 & .79 & -0.08 & 0.40 \\
\hline
\end{tabular}

Note. Responses were made on 7-point Likert-type scales ranging from 1 (not at all) to 7 (very much) for items measuring intensity and from 1 (never) to 7 (very much) for items measuring frequency, $r=$ rank-order stability coefficients, $\mathrm{d}=$ Latent Cohen's d based on True Intraindividual Change Models. $N=1412-1417$ due to missing data. 


\section{Table 4}

Estimated Intercorrelations Between Latent Factors of Self-Esteem

\begin{tabular}{|c|c|c|c|c|c|c|c|c|c|c|c|c|c|c|c|c|c|c|c|c|c|c|c|}
\hline $\begin{array}{l}\text { Measures of Self- } \\
\text { Esteem }\end{array}$ & 1 & 2 & 3 & 4 & 5 & 6 & 7 & 8 & 9 & 10 & 11 & 12 & 13 & 14 & 15 & 16 & 17 & 18 & 19 & 20 & 21 & 22 & 23 \\
\hline 1. Global SE T1 & & & & & & & & & & & & & & & & & & & & & & & \\
\hline 2. Global SE T2 & .83 & & & & & & & & & & & & & & & & & & & & & & \\
\hline 3. Global SE T3 & .83 & .90 & & & & & & & & & & & & & & & & & & & & & \\
\hline 4. Global SE T4 & .76 & .81 & .85 & & & & & & & & & & & & & & & & & & & & \\
\hline 5. Social Contact $\mathrm{T} 1$ & .65 & .57 & .57 & .53 & & & & & & & & & & & & & & & & & & & \\
\hline 6. Social Contact T2 & .54 & .67 & .60 & .56 & .85 & & & & & & & & & & & & & & & & & & \\
\hline 7. Social Contact T3 & .59 & .62 & .66 & .60 & .90 & .91 & & & & & & & & & & & & & & & & & \\
\hline 8. Social Contact T4 & .58 & .60 & .59 & .70 & .85 & .88 & .87 & & & & & & & & & & & & & & & & \\
\hline 9. Social Criticism T1 & .75 & .64 & .63 & .52 & .65 & .60 & .60 & .55 & & & & & & & & & & & & & & & \\
\hline 10. Social Criticism T2 & .68 & .78 & .69 & .61 & .57 & .73 & .63 & .61 & .85 & & & & & & & & & & & & & & \\
\hline 11. Social Criticism T3 & .64 & .70 & .76 & .63 & .59 & .69 & .74 & .63 & .80 & .87 & & & & & & & & & & & & & \\
\hline 12. Social Criticism T4 & .64 & .70 & .69 & .76 & .56 & .64 & .58 & .71 & .75 & .86 & .86 & & & & & & & & & & & & \\
\hline 13. Performance T1 & .80 & .66 & .63 & .63 & .54 & .42 & .53 & .47 & .67 & .61 & .57 & .54 & & & & & & & & & & & \\
\hline 14. Performance T2 & .66 & .77 & .70 & .67 & .45 & .53 & .52 & .49 & .54 & .69 & .58 & .65 & .77 & & & & & & & & & & \\
\hline 15. Performance T3 & .65 & .74 & .81 & .70 & .50 & .51 & .60 & .51 & .53 & .63 & .69 & .62 & .72 & .80 & & & & & & & & & \\
\hline 16. Performance T4 & .68 & .71 & .72 & .82 & .45 & .48 & .54 & .59 & .53 & .59 & .60 & .71 & .77 & .90 & .83 & & & & & & & & \\
\hline 17. Physical Appear. T1 & .61 & .50 & .55 & .52 & .54 & .45 & .49 & .47 & .51 & .44 & .44 & .38 & .46 & .34 & .35 & .35 & & & & & & & \\
\hline 18. Physical Appear. T2 & .54 & .66 & .63 & .59 & .49 & .57 & .52 & .53 & .43 & .54 & .50 & .51 & .42 & .50 & .47 & .48 & .81 & & & & & & \\
\hline 19. Physical Appear. T3 & .50 & .58 & .66 & .57 & .47 & .50 & .54 & .50 & .42 & .48 & .54 & .42 & .38 & .42 & .47 & .41 & .81 & .93 & & & & & \\
\hline 20. Physical Appear. T4 & .48 & .56 & .56 & .66 & .46 & .50 & .45 & .58 & .37 & .43 & .44 & .51 & .36 & .44 & .37 & .50 & .80 & .90 & .86 & & & & \\
\hline 21. Physical Ability T1 & .49 & .47 & .43 & .36 & .48 & .46 & .44 & .37 & .45 & .46 & .38 & .38 & .39 & .41 & .36 & .38 & .58 & .56 & .47 & .47 & & & \\
\hline 22. Physical Ability T2 & .38 & .54 & .46 & .45 & .42 & .49 & .41 & .42 & .31 & .51 & .39 & .46 & .32 & .44 & .39 & .38 & .41 & .61 & .53 & .47 & .86 & & \\
\hline 23. Physical Ability T3 & .42 & .47 & .50 & .42 & .39 & .40 & .45 & .42 & .38 & .44 & .46 & .45 & .36 & .37 & .43 & .39 & .45 & .57 & .60 & .49 & .80 & .86 & \\
\hline 24. Physical Ability T4 & .41 & .49 & .50 & .54 & .45 & .46 & .44 & .51 & .38 & .41 & .39 & .49 & .35 & .40 & .43 & .45 & .55 & .64 & .60 & .65 & .80 & .85 & .86 \\
\hline
\end{tabular}




\section{Rank-Order Stability and Mean-Level Change}

Across the measures of domain-specific self-esteem, rank-order stability coefficients over the 6 years of assessment ranged from $r=.74(95 \%$ CI $[.67, .81])$ for social criticism self-esteem to $r=.87(95 \% \mathrm{CI}[.83, .90])$ for social contact self-esteem, all $p \mathrm{~s}<.001 .{ }^{8}$ Global self-esteem exhibited a rank-order stability of $r=.77(95 \%$ CI $[.70, .83], p<.001)$. When comparing the coefficients for the rank-order stability between global self-esteem and the measures of domainspecific self-esteem, we found overlapping confidence intervals. This suggests that domainspecific self-esteem was as stable as global self-esteem.

Results from True Intraindividual Change Models revealed that, for global self-esteem and the social, performance, and physical appearance self-esteem domains, the mean-level change scores were positive, indicating an increase in self-esteem from Time 1 to Time 4 . The effect sizes, however, were rather small ( $d=0.12$ for global self-esteem, and $d \mathrm{~s}=0.09$ and 0.11 for social contact and social criticism self-esteem, respectively). Mean-level change in physical ability self-esteem across 6 years was negative and significantly different from zero $(M=-0.08$, $p=.035,95 \%$ CI $[-0.14,-0.01])$. On average, participants experienced a decrease in physical ability self-esteem over the course of 6 years. ${ }^{3}$ As could be observed from the variance of the change scores (Table 3), people differed significantly from each other in how much they changed in global and domain-specific self-esteem across the 6 years of assessment.

\section{Trait and Occasion-Specific Components of Self-Esteem}

Latent TSO model analyses revealed that for all measures of self-esteem, the variance explained by a stable trait factor was larger than the variance explained by an occasion-specific factor (see Table 5). The proportion of variance in self-esteem accounted for by a trait factor ranged from $77 \%$ for global self-esteem to $88 \%$ for social contact self-esteem. Domain-specific self-esteem exhibited a proportion of trait variance that was comparable to that of global selfesteem. For both global self-esteem and domain-specific self-esteem, the trait variances and 
occasion-specific variances were significantly different from zero, thus highlighting the utility of the TSO model for the present data. Furthermore, for all measures of self-esteem, the trait variance was significantly larger than the occasion-specific variance. Our results thus indicated that global and domain-specific self-esteem have a strong trait component. Furthermore, the auto-regressive effects between occasion-specific factors of neighboring time points were significant for global self-esteem $(\beta=0.40, p=.001)$, social criticism self-esteem $(\beta=0.34, p=$ $.006)$, and physical ability self-esteem $(\beta=0.36, p=.038)$. The auto-regressive effects for the other domains of self-esteem were not significant. Our results thus suggested spillover effects between occasion-specific factors for global self-esteem as well as the social and physical domain after controlling for the influence of a stable trait.

\section{Table 5}

Trait Variance, Occasion Specific Variance, and Auto-Regressive Effects from Latent Trait-State Occasion Models

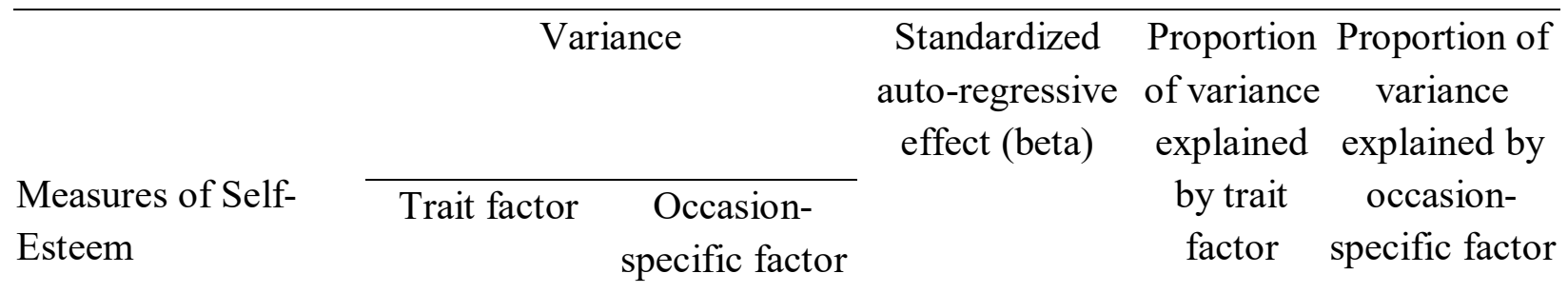

\begin{tabular}{|c|c|c|c|c|c|}
\hline Global Self-Esteem & $\begin{array}{c}0.864 * * \\
{[0.729,0.999]}\end{array}$ & $\begin{array}{c}0.258 * * \\
{[0.169,0.348]}\end{array}$ & $\begin{array}{c}0.403 * * \\
{[0.161,0.645]}\end{array}$ & $77 \%$ & $23 \%$ \\
\hline Social Contact & $\begin{array}{c}1.776^{* *} \\
{[1.597,1.954]}\end{array}$ & $\begin{array}{c}0.234 * * \\
{[0.190,0.277]}\end{array}$ & $\begin{array}{c}-0.109 \\
{[-0.331,0.113]}\end{array}$ & $88 \%$ & $12 \%$ \\
\hline Social Criticism & $\begin{array}{c}1.315^{* *} \\
{[1.128,1.503]}\end{array}$ & $\begin{array}{c}0.368^{* *} \\
{[0.254,0.483]}\end{array}$ & $\begin{array}{c}0.344 * * \\
{[0.100,0.588]}\end{array}$ & $78 \%$ & $22 \%$ \\
\hline Performance & $\begin{array}{c}0.749 * * \\
{[0.651,0.846]}\end{array}$ & $\begin{array}{c}0.200 * * \\
{[0.158,0.241]}\end{array}$ & $\begin{array}{c}0.028 \\
{[-0.195,0.215]}\end{array}$ & $79 \%$ & $21 \%$ \\
\hline Physical Appearance & $\begin{array}{c}1.564 * * \\
{[1.401,1.727]}\end{array}$ & $\begin{array}{c}0.362^{* *} \\
{[0.231,0.374]}\end{array}$ & $\begin{array}{c}0.141 \\
{[-0.103,0.384]}\end{array}$ & $84 \%$ & $16 \%$ \\
\hline
\end{tabular}


Physical Ability

$0.778 * *$

$0.199 * *$

$0.358 *$

$80 \%$

$20 \%$

$[0.626,0.930][0.114,0.284] \quad[0.019,0.697]$

Note. $95 \%$ confidence intervals are included in parentheses. $N=1412-1417$ due to missing data. $* \mathrm{p}<.05 . * * \mathrm{p}<.01$

\section{Top-Down and/or Bottom-Up?}

In order to test classical top-down and bottom-up theories, we extended previous empirical research and followed two analytical perspectives by focusing on true intraindividual change and occasion-specific intraindividual change.

Mutual Influences on True Intraindividual Change. Coefficients from the bivariate TICMs are displayed in Tables 6 and 7. Three significant top-down effects were found (see Table 6). Participants higher in global self-esteem at Time 1 showed an increase in social criticism self-esteem $(b=0.17,95 \%$ CI $[0.017,0.329])$ and in performance self-esteem $(b=$ $0.17,95 \% \mathrm{CI}[0.006,0.343])$ across the next 2 years of measurement. Moreover, change in global self-esteem significantly predicted change in performance self-esteem $(b=0.31,95 \% \mathrm{CI}$ $[0.041,0.588])$, indicating that participants who experienced a 2-year increase in global selfesteem also exhibited an increase in performance self-esteem 2 years later. However, we did not find any evidence for bottom-up effects.

The bivariate TICMs additionally allowed us to compute the following covariances: the associations between the initial levels of global self-esteem and domain-specific self-esteem (Figure 1, the A coefficient) and the associations between the residuals of the change factors of global and domain-specific self-esteem at subsequent time points (Figure 1, the B coefficients). In line with previous research, the results revealed that the initial level of global self-esteem was significantly positively associated with every initial level of the domains of self-esteem with coefficients (A) ranging from $r=.50(95 \% \mathrm{CI}[.431, .562])$ for physical ability self-esteem to $r=$ $.82(95 \%$ CI $[.785, .855])$ for performance self-esteem (see Table 7 for more detail). Moreover, we found that change in global self-esteem was significantly positively related to change in 
domain-specific self-esteem within the same time interval for all domains of self-esteem with coefficients $(B)$ ranging from $b=0.12(95 \% \mathrm{CI}[0.094,0.154])$ for physical ability self-esteem to $\mathrm{b}=0.22(95 \%$ CI $[0.182,0.254])$ for social criticism self-esteem. Thus, our results highlight that global self-esteem and domain-specific self-esteem co-developed over a period of 2 years, that is, the larger an individual's increase in global-self-esteem, the larger their increase in domainspecific self-esteem and vice versa.

Mutual Influences on Occasion-Specific Intraindividual Change. As displayed in Table 8, there was one significant top-down effect. The occasion-specific factor in global selfesteem at a previous time point positively predicted the occasion-specific factor in performance self-esteem $(b=0.44,95 \%$ CI $[0.077,0.802]$ at a subsequent time point. Participants who experienced occasion-specific deviations (e.g., an increase) in global self-esteem exhibited occasion-specific deviations (e.g., an increase) in performance self-esteem 2 years later. There were, again, no bottom-up effects.

The bivariate TSO additionally allowed us to compute the following covariances (see Table 9): the associations between the stable trait factors of global and domain-specific selfesteem (Figure 2, the A coefficient), between the initial occasion-specific factors of global selfesteem and domain-specific self-esteem at Time 1 (Figure 2, the B coefficient), and between the residuals of the occasion-specific factors of global and domain-specific self-esteem at subsequent time points (Figure 2, the $\mathrm{C}$ coefficients). Our analyses showed that the stable trait factor of global self-esteem was significantly positively associated with each stable trait factor of domainspecific self-esteem (A) with coefficients ranging from $r=.52$ (95\% CI $[.438, .598])$ for physical ability self-esteem to $r=.82(95 \%$ CI $[.789, .859])$ for performance self-esteem. Furthermore, occasion-specific deviations in global self-esteem and in every domain of self-esteem at a specific time point were significantly positively related even when the stable trait factor was controlled for. The initial correlations (B) ranged from $r=.55$ (95\% CI $[.388, .709])$ for physical 
ability self-esteem to $r=.79(95 \%$ CI $[.671, .902])$ for performance self-esteem, and the residual covariances ranged from $b=0.09(95 \% \mathrm{CI}[0.044,0.140])$ for physical ability to $b=0.19(95 \%$ CI $[0.133,0.246])$ for social criticism self-esteem. In sum, these results show that positive associations between global and domain-specific self-esteem within the same time frame can be found for both the trait factors and the occasion-specific factors that are decomposed in the TSO models.

\section{Discussion}

The goal of the present research was to investigate whether classical top-down and bottom-up models on the mutual influence between global and domain-specific self-esteem could withstand a thorough test by applying elaborate analytical methods in a four-wave preregistered longitudinal study of adults.

\section{Global Self-Esteem and Domain-Specific Self-Esteem are Related in a Top-Down Fashion}

In the present study, we investigated whether intraindividual change in domain-specific self-esteem could be explained from the top down by global self-esteem or whether intraindividual change in global self-esteem could be explained from the bottom up by domainspecific self-esteem. Overall, and across two analytical approaches, our results were in favor of the top-down approach. Individuals with a higher level of global self-esteem exhibited an increase in domain-specific self-esteem 2 years later. An increase in global self-esteem also predicted a subsequent increase in domain-specific self-esteem. By contrast, we found no evidence in support of the bottom-up approach in the present sample.

Our results are in line with the perspective that is presented by the affective model of self-esteem development (Brown \& Dutton, 1995; Brown et al., 2001), which argues that global perceptions of self-worth are not based on evaluations of one's competencies or qualities in specific domains but instead influence domain-specific self-evaluations. Our results are contrary to bottom-up approaches such as the ones offered by James (1890) and Harter (2006), who 


\section{Table 6}

Top-Down and Bottom-Up Effects From Bivariate True Intraindividual Change Models

\begin{tabular}{|c|c|c|c|c|}
\hline \multirow[t]{2}{*}{$\begin{array}{l}\text { Measures of Self- } \\
\text { Esteem }\end{array}$} & \multicolumn{2}{|c|}{$\begin{array}{c}\text { Top-Down } \\
\text { Global Self-Esteem }=>\text { Domain-Specific Self-Esteem }\end{array}$} & \multicolumn{2}{|c|}{$\begin{array}{c}\text { Bottom-Up } \\
\text { Domain-Specific Self-Esteem }=>\text { Global Self-Esteem }\end{array}$} \\
\hline & Initial Level -> Change & Change $_{\mathrm{T}}->$ Change $_{\mathrm{T}+1}$ & Initial Level -> Change & Change $_{\mathrm{T}}->$ Change $_{\mathrm{T}+1}$ \\
\hline Social Contact & $-0.006[-0.133,0.120]$ & $0.037[-0.238,0.312]$ & $0.038[-0.037,0.133]$ & $0.009[-0.188,0.206]$ \\
\hline Social Criticism & $0.173 *[0.017,0.329]$ & $0.235[-0.062,0.532]$ & $-0.003[-0.106,0.101]$ & $-0.026[-0.203,0.152]$ \\
\hline Performance & $0.174 *[0.006,0.343]$ & $0.314 *[0.041,0.588]$ & $-0.044[-0.235,0.148]$ & $-0.023[-0.213,0.168]$ \\
\hline Physical Appearance & $0.083[-0.031,0.198]$ & $-0.045[-0.382,0.292]$ & $0.013[-0.063,0.088]$ & $-0.029[-0.234,0.175]$ \\
\hline Physical Ability & $-0.021[-0.111,0.068]$ & $0.043[-0.178,0.264]$ & $0.059[-0.037,0.155]$ & $0.002[-0.252,0.256]$ \\
\hline
\end{tabular}

Note. Cells present unstandardized cross-lagged regression coefficients from True Intraindividual Change Model analyses. 95\% confidence intervals are included in parentheses. $N=1417$.

$* p<.05$.

\section{Table 7}

Initial Level Correlation and Covariance of Change Between Global Self-Esteem and Domain-Specific Self-Esteem

\begin{tabular}{lll}
\hline Measures of Self- Esteem & Initial Level Correlation & Covariance of Change \\
\hline Social Contact & $0.662^{* * *}[0.614,0.710]$ & $0.199 * * *[0.164,0.234]$ \\
Social Criticism & $0.759^{* * *}[0.719,0.799]$ & $0.218^{* * *}[0.182,0.254]$ \\
Performance & $0.820^{* * *}[0.785,0.855]$ & $0.179^{* * *}[0.147,0.211]$ \\
Physical Appearance & $0.610^{* * *}[0.556,0.664]$ & $0.209^{* * *}[0.174,0.245]$ \\
Physical Ability & $0.497 * * *[0.431,0.562]$ & $0.124 * * *[0.094,0.154]$
\end{tabular}

Note. Cells present coefficients from True Intraindividual Change Model analyses. Initial level correlation $=$ the correlation between the initial levels of global self-esteem and domain-specific self-esteem, Covariance of change $=$ the covariance between the residuals from latent change factors of global and domain-specific self-esteem. 95\% confidence intervals are included in parentheses. $N=1417$.

$* * * p<.001$. 


\section{Table 8}

Top-Down and Bottom-Up Effects From Bivariate Trait-State-Occasion Models

Top-Down
Measures of Self-Esteem $\quad$ Global Self-Esteem $=>$ Domain-Specific Self-Esteem

Social Contact

$0.200[-0.127,0.527]$

Social Criticism $\quad 0.420[-0.019,0.859]$

Performance

$0.440 *[0.077,0.802]$

Physical Appearance $\quad 0.225[-0.086,0.536]$

Physical Ability

$-0.003[-0.297,0.291]$

Bottom-Up

Domain-Specific Self-Esteem $=>$ Global Self-Esteem

Note. Cells present unstandardized cross-lagged regression coefficients between occasion-specific factors from Trait-State-Occasion model analyses. $95 \%$ confidence intervals are included in parentheses. $N=1417$.

$* p<.05$.

\section{Table 9}

Trait Correlation, Initial Correlation and Covarying Residuals Between Occasion-Specific Factors in Global Self-Esteem and Domain-Specific Self-Esteem

\begin{tabular}{lccc}
\hline Measures of Self- Esteem & Trait Correlation & Initial Correlation & Covariance Between Residuals \\
\hline Social Contact & $0.682^{* * *}[0.636,0.729]$ & $0.638^{* * *}[0.474,0.803]$ & $0.136^{* * *}[0.092,0.181]$ \\
Social Criticism & $0.762^{* * *}[0.715,0.810]$ & $0.714^{* * *}[0.576,0.852]$ & $0.190^{* * *}[0.133,0.246]$ \\
Performance & $0.824^{* * *}[0.789,0.859]$ & $0.786^{* * *}[0.671,0.902]$ & $0.120^{* * *}[0.083,0.158]$ \\
Physical Appearance & $0.648^{* * *}[0.598,0.699]$ & $0.548^{* * *}[0.388,0.709]$ & $0.137^{* * *}[0.093,0.181]$ \\
Physical Ability & $0.518^{* * *}[0.438,0.598]$ & $0.499^{* * *}[0.243,0.755]$ & $0.092^{* * *}[0.044,0.140]$ \\
\hline
\end{tabular}

Note. Cells present coefficients from Trait-State-Occasion model analyses. Trait correlation (initial correlation) $=$ the correlation between the trait factors (initial levels of occasion-specific factors) in global self-esteem and domain-specific self-esteem. Covariance between residuals $=$

covariance coefficient between the residuals of occasion-specific factors of global and domain-specific self-esteem. $95 \%$ confidence intervals are included in parentheses. $N=1417$.

$* * * p<.001$. 
argued that global self-esteem develops from domain-specific self-evaluations.

Similarly, our findings also go against the prominent work conducted by Shavelson et al. (1976), who claimed that substantial changes in domain-specific self-evaluations would lead to changes in global self-esteem.

Top-down effects were shown for two domains of self-esteem in particular (i.e., performance self-esteem and self-esteem regarding social criticism). Our findings may reflect the idea that the development of global self-esteem would be related to the development of self-esteem in domains for which correlations with global self-esteem are stronger, such as performance self-esteem (see Orth et al., 2021). This idea, however, does not explain why we found no bottom-up effects but top-down effects in these domains. Our results are in line with the top-down effects on academic self-esteem that have been reported in the literature (e.g., Trautwein et al., 2006). Still, the fact that we found only a few top-down effects stresses the importance of replicating these findings in future research. There is no conceptual difference between the domains that were affected by top-down effects and those that were not affected. There was also no difference with respect to stability or variance that would offer a straightforward statistical explanation for why top-down effects were found in some domains but not in the others. Any post hoc explanations would therefore be highly speculative. With the evidence at hand, we therefore prefer to focus on the general pattern of results: In the present sample, we found no evidence whatsoever for bottom-up effects, but some evidence for top-down effects. To note, whereas bottom-up effects were not shown for any self-esteem domain, top-down effects were evident across all analytical perspectives: level on true intraindividual change (TICM), true intraindividual change on true intraindividual change (TICM), and occasion-specific intraindividual change on occasion-specific intraindividual change (TSO).

Importantly, most of the classical top-down and bottom-up approaches have addressed development and change in global and domain-specific self-esteem (Brown et al., 2001; 
Harter, 2006; James, 1890; Shavelson \& Bolus, 1982), but the studies conducted so far usually did not apply study designs or statistical models that were suited to investigate whether intraindividual change in global self-esteem was related to intraindividual change in specific domains (or vice versa). Our study extends previous research by providing evidence that there were effects from the top down on intraindividual change. By applying a 4-wave longitudinal design and novel analytical approaches, the present study is the first to demonstrate that regardless of where an individual started on global or domain-specific selfesteem, change in global self-esteem predicted subsequent change in performance self-esteem 2 years later. Our study, thus, provides important evidence for classical top-down models which stated that global self-esteem is the basis for the establishment of domain-specific selfevaluations (Brown et al., 2001). A positive development in global self-esteem seems to facilitate a later positive development in performance self-esteem. Furthermore, our results from the bivariate TSO models extend previous findings by pertaining to occasion-specific factors in global and domain-specific self-esteem: Occasion-specific deviations in global selfesteem predicted occasion-specific deviations in performance self-esteem 2 years later even when we controlled for the influence of trait factors that were stable across the entire study period. Disentangling the stable (trait) aspects of self-esteem from the malleable (occasionspecific) aspects of self-esteem, this model enabled us to capture intra-individual processes that were central to classical theorizing but not yet adequately modeled in empirical studies.

Our findings have important implications for the development of global and domainspecific self-esteem in adulthood. Some proponents of bottom-up approaches have argued that global self-esteem develops from domain-specific self-evaluations (Harter et al., 1998; Shavelson et al., 1976), but the present findings challenge this view. In contrast to this view, our results suggest that domain-specific evaluations develop from general perceptions of selfworth in a top-down fashion. The development of self-esteem seems to be influenced more by how people generally feel about themselves (i.e., more affective processes) than by specific 
self-evaluations in domains of self-esteem (i.e., more rational, judgmental processes; Brown \& Marshall, 2006). This implies that self-esteem changes in specific domains (e.g., performance, social life) that might be triggered by success or failure and positive or negative feedback relevant to these domains, are unlikely to have a long-term impact on global selfesteem, at least for highly educated western populations that are similar to our sample. It is rather global self-esteem that influences development in the domains or perhaps moderates the impact of environmental influences on domain-specific self-esteem (Brown et al., 2001).

\section{Global Self-Esteem and Domain-Specific Self-Esteem are Intertwined in a "Vertical"}

\section{Fashion}

In addition to top-down and bottom-up effects, Marsh and Yeung (1998) mentioned so-called "horizontal" effects on the longitudinal flow between global and domain-specific self-esteem, that is, longitudinal effects within the same constructs (i.e., auto-regression). Based on the present results, we think it is necessary to extend these concepts by introducing another concept that involves "vertical" associations. When we mention vertical associations, we are referring (a) to the concordant longitudinal development of global and domain-specific self-esteem within the same time interval (covariance of true intraindividual change) and (b) to the concordant occasion-specific deviations of global and domain-specific self-esteem at the same occasion (covariance of occasion-specific intraindividual change). In the present study, we found consistent evidence for such parallel changes in global and domain-specific self-esteem across intervals of 2 years. Participants who exhibited an increase in global selfesteem also experienced an increase in domain-specific self-esteem within the same time frame. We found such vertical associations in all self-esteem domains, which raises questions about possible explanations for these findings. First, these results may point to bidirectional, probably short-term influences between global and domain-specific self-esteem. For example, it may be that individuals high in physical self-esteem engage in exercising behaviors that lead to winning a sports competition. These behaviors and outcomes may in turn be associated 
with a short-term increase in global self-esteem, and this increase may help to engage in similar activities that lead to an increase in physical self-esteem etc. Given the significant covariances of change in the present study, this reciprocal interplay may even play out over the life course, probably contributing to the development of self-esteem. Furthermore, our results also point to similar underlying processes that may be responsible for the development of global self-esteem and domain-specific self-esteem within the same time frame (see Allemand \& Martin, 2016). For example, genetic factors, illness, or the mastering of life tasks such as getting an education may be equally important for intraindividual changes in both global and domain-specific self-esteem. It is up to future research to investigate these factors of influence and the role of correlated change in self-esteem development.

\section{Domain-Specific Self-Esteem is a Stable, Trait-Like Construct}

In our review of the literature, our attention was also drawn to the fact that classical perspectives on top-down and bottom-up processes in self-esteem also made assumptions about the stability of different forms of self-esteem. Some scholars (i.e., Brown et al., 2001; Shavelson et al., 1976) have argued that global self-esteem is a stable construct, whereas domain-specific self-esteem is rather unstable.

When comparing global and domain-specific self-esteem with respect to the different aspects of stability, a clear pattern emerged: We found that domain-specific self-esteem was as stable as global self-esteem with respect to both rank-order stability and mean-level change. Therefore, our results are in line with previous argumentations that have characterized both global and domain-specific self-esteem as trait-like (e.g., Fleming \& Courtney, 1984; Janis \& Field, 1959). Notably, stability coefficients for self-esteem (global and domain-specific alike) in the present study were of similar size as those that had been reported for "core trait" measures for similar retest intervals (e.g., the Big Five; Anusic \& Schimmack, 2016; Borghuis et al., 2017; Wortman et al., 2012). Eventually, our findings may call the common classification of self-esteem as a "surface characteristic" (Asendorpf \& van 
Aken, 2003) into question (see also Kuster \& Orth, 2013, on the stability of global selfesteem), especially in adulthood. In support of this finding, our TSO models showed that a considerable amount of variance in self-esteem was due to a stable trait. This finding is in line with past results on global self-esteem (Donnellan et al., 2012; Orth \& Luciano, 2015) and once again comparable to what others have found for the Big Five personality traits (e.g., Wagner et al., 2019). Importantly, our study extends these findings to include domain-specific self-esteem, thus contradicting several prominent scholars who conceptualized domainspecific self-esteem as a rather unstable person characteristic (e.g., Brown \& Marshall, 2006; Shavelson et al., 1976). Our results provide ample evidence that global and domain-specific self-esteem are equally trait-like. Please find a more elaborate discussion on the stability of global and domain-specific self-esteem in the Supplement S2 (https://osf.io/h4qwt/).

\section{Strengths, Limitations, and Directions for Future Research}

The present study is characterized by a number of strengths. The pattern of results was consistent across various aspects of self-esteem development and different analytical approaches: While we found evidence for top-down effects and vertical effects, there was no evidence for bottom-up effects whatsoever. We would like to highlight that the study was preregistered before data of Time 3 were analyzed and before data of Time 4 were collected.

Despite calls for more rigorous and transparent research in psychology, preregistration is still rare in longitudinal studies on self-esteem. Furthermore, the study used a full scale measuring global and domain-specific self-esteem with five to seven items per subscale. Our study thus ensures the highest quality standards regarding content validity and reliability and stands out positively against longitudinal studies on global self-esteem that are sometimes limited by using single item measures or short scales.

To our knowledge, the present research is the only study investigating the mutual influence of global and domain-specific self-esteem in a sample of adults with a large age range. The meta-analysis by Orth et al. (2021) on the longitudinal development of domain- 
specific self-esteem presented two studies in young adults only. In the current study, we analyzed a sample with a mean age that closely resembled the average age of the German population (44.5 years of age; DESTATIS, 2020) and a very large age range from young to old adulthood. Still, investigating the current research questions using a larger, age-balanced sample that allows for comparisons between age groups could help to investigate whether the results are specific to certain developmental periods or can be generalized across the life span.

Furthermore, participants in our sample were on average more highly educated, and women were overrepresented. The presented results are, thus, limited in that they stem from a non-representative adult sample from Germany. Future studies replicating our findings in non-WEIRD samples (Henrich et al., 2010) are thus needed to test the generalizability of our results.

In the present study, we argued that global self-esteem is a driving force in the development of domain-specific self-evaluations in adulthood. However, our study did not allow us to draw conclusions about the early development of global and domain-specific selfesteem in childhood and adolescence. In the light of evidence suggesting lower stabilities in child and adolescent populations (e.g., Asendorpf \& Van Aken, 1993; Marsh et al., 1983), in the future, researchers may want to investigate the longitudinal development and mutual influence of global and domain-specific self-esteem in children and adolescents by employing similar analytical strategies such as those presented in this study. More generally, there may be subpopulations that differ from each other with respect to exhibiting either top-down or bottom-up effects or both types of effects. Future research may thus want to aim at identifying such subpopulations, for example, by using structural equation mixture modeling.

Furthermore, despite using a longitudinal design and sophisticated data analyses, our study does not allow for drawing conclusions regarding causality in the way an experimental design could. Apart from ethical considerations regarding the manipulation of personality traits, there would be practical limitations in classical laboratory experiments that could target 
momentary (state-) self-esteem but most probably not trait self-esteem. To overcome these issues, future studies might investigate top-down and bottom-up effects in the context of randomized studies on long-term self-esteem change through interventions such as psychotherapy.

In the present study, we investigated time intervals of 2 years and covered a time span of 6 years in total. The stability of and change in self-esteem as well as top-down and bottomup processes must be interpreted within this time frame, which may be considered rather broad. Future research may therefore use shorter retest intervals to investigate these issues. For example, some have reasoned that domain-specific self-esteem might be momentarily affected by recent domain-specific events but might revert to baseline when the situation in the respective domain normalizes (e.g., Coopersmith, 1967). In this regard, researchers may want to investigate the short-term fluctuations in global and domain-specific self-esteem in response to specific self-esteem-relevant situations, for example, by using an experience sampling design and state-like measures of global and domain-specific self-esteem in future studies (e.g., Geukes et al., 2017). Such an approach would also help to build a connection of top-down and bottom-up perspectives with theoretical perspectives on the influence of recent events that might affect one's social inclusion, status, and the like (Kirkpatrick \& Ellis, 2001; Leary et al., 1995).

Another direction for future research might be to investigate longer time spans. It might be possible that top-down or bottom-up effects can be detected more readily when more (variance in the) change occurs, which becomes more likely with longer time intervals. Selfesteem has been shown to be less stable when longer time intervals are under investigation (e.g., Kuster \& Orth, 2013; Pullmann \& Allik, 2000). Although we used sufficiently large time intervals of 2 years in terms of the robustness of the TSO models (Cole et al., 2005), analyzing even longer time intervals might help to investigate whether spillover effects between occasion-specific factors at different time points are particularly large for certain 
occasion-specific circumstances. For example, there may be external events such as retirement that occur at a specific point in time but have a lasting effect on self-esteem (e.g., Bleidorn \& Schwaba, 2018) independent of a stable trait factor.

In the present study, we focused on the mutual influence between global and domainspecific self-esteem in a top-down and bottom-up fashion. Another direction for future research may be to focus on how global and domain-specific self-esteem each change in response to life events or internal factors. For example, changes in occupational or educational status (Orth et al., 2012; Wagner et al., 2013) or in social relationships (Harris \& Orth, 2019; Krauss et al., 2020) might help to explain individual differences in the direction and magnitude of change. At the same time, individual differences in the extent to which people's self-esteem is contingent on interpersonal relationships, physical appearance, or performance at work (e.g., Crocker et al., 2003; Rentzsch \& Gross, 2015) may explain changes in specific domains such as social contact, physical appearance, or performance selfesteem. The present results on vertical effects, however, seem to suggest that the search for common causes of development and change in global and domain-specific self-esteem might be the most promising area for future research. 


\section{References}

Allemand, M., \& Martin, M. (2016). On correlated change in personality. European Psychologist, 21(4), 237-253. https://doi.org/10.1027/1016-9040/a000256

Anusic, I., \& Schimmack, U. (2016). Stability and change of personality traits, self-esteem, and well-being: Introducing the meta-analytic stability and change model of retest correlations. Journal of Personality and Social Psychology, 110(5), 766-781. https://doi.org/10.1037/pspp0000066

Asendorpf, J. B., \& Van Aken, M. A. (1993). Deutsche Versionen der Selbstkonzeptskalen von Harter [German versions of Harter's self-concept scales for children]. Zeitschrift für Entwicklungspsychologie und Pädagogische Psychologie, 25(1), 64-86.

Asendorpf, J. B., \& van Aken, M. A. G. (2003). Personality-relationship transaction in adolescence: Core versus surface personality characteristics. Journal of Personality, 71(4), 629-666. https://doi.org/10.1111/1467-6494.7104005

Baumeister, R. F. (1998). The self. In D. T. Gilbert, S. T. Fiske, \& G. Lindzey (Eds.), The handbook of social psychology (4th ed., pp. 680-740). McGraw.

Bleidorn, W., \& Schwaba, T. (2018). Retirement is associated with change in self-esteem. Psychology and Aging, 33(4), 586-594. https://doi.org/10.1037/pag0000253

Bollen, K. A., \& Curran, P. J. (2006). Latent curve models: A structural equation perspective. Wiley.

Borghuis, J., Denissen, J. J. A., Oberski, D., Sijtsma, K., Meeus, W. H. J., Branje, S., Koot, H. M., \& Bleidorn, W. (2017). Big Five personality stability, change, and codevelopment across adolescence and early adulthood. Journal of Personality and Social Psychology. https://doi.org/10.1037/pspp0000138

Brown, J. D., \& Dutton, K. A. (1995). The thrill of victory, the complexity of defeat: Selfesteem and people's emotional reactions to success and failure. Journal of Personality and Social Psychology, 68(4), 712-722. https://doi.org/10.1037/0022-3514.68.4.712 
Brown, J. D., Dutton, K. A., \& Cook, K. E. (2001). From the top down: Self-esteem and selfevaluation. Cognition and Emotion, 15(5), 615-631. https://doi.org/10.1080/02699930143000004

Brown, J. D., \& Marshall, M. A. (2006). The three faces of self-esteem. In M. H. Kernis (Ed.), Self-esteem issues and answers: A sourcebook of current perspectives. (pp. 4-9). Psychology Press.

Chan, D. W. (1997). Self-concept domains and global self-worth among Chinese adolescents in Hong Kong. Personality and Individual Differences, 22(4), 511-520. https://doi.org/10.1016/S0191-8869(96)00223-1

Cheung, G. W., \& Rensvold, R. B. (2002). Evaluating goodness-of-fit indexes for testing measurement invariance. Structural Equation Modeling, 9(2), 233-255. https://doi.org/10.1207/s15328007sem0902_5

Chung, J. M., Hutteman, R., van Aken, M. A. G., \& Denissen, J. J. A. (2017). High, low, and in between: Self-esteem development from middle childhood to young adulthood. Journal of Research in Personality, 70, 122-133. https://doi.org/10.1016/j.jrp.2017.07.001

Cole, D. A., Martin, N. C., \& Steiger, J. H. (2005). Empirical and conceptual problems with longitudinal trait-state models: Introducing a Trait-State-Occasion Model. Psychological Methods, 10(1), 3-20. https://doi.org/10.1037/1082-989X.10.1.3

Cole, D. A., Maxwell, S. E., Martin, J. M., Peeke, L. G., Seroczynski, A. D., Tram, J. M., Hoffman, K. B., Ruiz, M. D., Jacquez, F., \& Maschman, T. (2001). The development of multiple domains of child and adolescent self-concept: A cohort sequential longitudinal design. Child Development, 72(6), 1723-1746. https://doi.org/10.1111/1467-8624.00375

Coopersmith, S. (1967). The antecedents of self-esteem. Freeman.

Crocker, J., Luhtanen, R. K., Cooper, M. L., \& Bouvrette, A. (2003). Contingencies of self- 
worth in college students: theory and measurement. Journal of Personality and Social Psychology, 85(5), 894-908. https://doi.org/10.1037/0022-3514.85.5.894

Donnellan, M. B., Kenny, D. A., Trzesniewski, K. H., Lucas, R. E., \& Conger, R. D. (2012). Using trait-state models to evaluate the longitudinal consistency of global self-esteem from adolescence to adulthood. Journal of Research in Personality, 46(6), 634-645. https://doi.org/10.1016/j.jrp.2012.07.005

Donnellan, M. B., Trzesniewski, K. H., Conger, K. J., \& Conger, R. D. (2007). A three-wave longitudinal study of self-evaluations during young adulthood. Journal of Research in Personality, 41(2), 453-472. https://doi.org/10.1016/j.jrp.2006.06.004

Enders, C. K. (2010). Applied missing data analysis. Guilford.

Fleming, J. S., \& Courtney, B. E. (1984). The dimensionality of self-esteem: II. Hierarchical facet model for revised measurement scales. Journal of Personality and Social Psychology, 46(2), 404-421. https://doi.org/10.1037/0022-3514.46.2.404

Fleming, J. S., \& Watts, W. A. (1980). The dimensionality of self-esteem: Some results of a college sample. Journal of Personality and Social Psychology, 39(5), 921-929. https://doi.org/10.1037/0022-3514.39.5.921

Geukes, K., Nestler, S., Hutteman, R., Dufner, M., Küfner, A. C. P., Egloff, B., Denissen, J. J. A., \& Back, M. D. (2017). Puffed-up but shaky selves: State self-esteem level and variability in narcissists. Journal of Personality and Social Psychology, 112(5), 769786. https://doi.org/10.1037/pspp0000093

Gogol, K., Brunner, M., Preckel, F., Goetz, T., \& Martin, R. (2016). Developmental dynamics of general and school-subject-specific components of academic self-concept, academic interest, and academic anxiety. Frontiers in Psychology, 7. https://doi.org/10.3389/fpsyg.2016.00356

Hamaker, E. L., Kuiper, R. M., \& Grasman, R. P. P. P. (2015). A critique of the cross-lagged panel model. Psychological Methods, 20(1), 102-116. 
https://doi.org/10.1037/a0038889

Harris, M. A., \& Orth, U. (2019). The link between self-esteem and social relationships: A meta-analysis of longitudinal studies. Journal of Personality and Social Psychology. https://doi.org/10.1037/pspp0000265

Harris, M. A., Wetzel, E., Robins, R. W., Donnellan, M. B., \& Trzesniewski, K. H. (2018). The development of global and domain self-esteem from ages 10 to 16 for MexicanOrigin youth. International Journal of Behavioral Development, 42(1), 4-16. https://doi.org/10.1177/0165025416679744

Harter, S. (2006). The development of self-esteem. In M. H. Kernis (Ed.), Self-esteem issues and answers: A sourcebook of current perspectives. (pp. 144-150). Psychology Press.

Harter, S., Whitesell, N. R., \& Junkin, L. J. (1998). Similarities and differences in domainspecific and global self-evaluations of learning-disabled, behaviorally disordered, and normally achieving adolescents. American Educational Research Journal, 35(4), 653680. https://doi.org/10.2307/1163462

Heatherton, T. F., \& Polivy, J. (1991). Development and validation of a scale for measuring state self-esteem. Journal of Personality and Social Psychology, 60(6), 895-910. https://doi.org/10.1037/0022-3514.60.6.895

Henrich, J., Heine, S. J., \& Norenzayan, A. (2010). The weirdest people in the world? RatSWD Working Papers 139, German Data Forum (RatSWD).

Huang, C. (2010). Mean-level change in self-esteem from childhood through adulthood: Meta-analysis of longitudinal studies. Review of General Psychology, 14(3), 251-260. https://doi.org/10.1037/a0020543

James, W. (1890). The principles of psychology, Vol I. Henry Holt and Co. https://doi.org/10.1037/10538-000

Janis, I. L., \& Field, P. B. (1959). Sex differences and personality factors related to persuasibility. In C. I. Hovland \& I. L. Janis (Eds.), Personality and persuasibility (pp. 
55-68). Yale University Press.

Kenny, D. A., \& Zautra, A. (1995). The trait-state-error model for multiwave data. Journal of Consulting and Clinical Psychology, 63(1), 52-59. https://doi.org/10.1037/0022$\underline{006 X .63 .1 .52}$

Kernis, M. H. (2005). Measuring self-esteem in context: The importance of stability of selfesteem in psychological functioning. Journal of Personality, 73(6), 1569-1605. https://doi.org/10.1111/j.1467-6494.2005.00359.x

Kernis, M. H. (2006). Self-esteem issues and answers: A sourcebook of current perspectives. Psychology Press.

Kirkpatrick, L. A., \& Ellis, B. J. (2001). An evolutionary approach to self-esteem: Multiple domains and multiple functions. In G. J. O. Fletcher \& M. S. Clark (Eds.), The Blackwell handbook of social psychology, Vol. 2: Interpersonal Processes (pp. 411436). Oxford, UK: Blackwell. [Reprinted (2004) in M. B. Brewer \& M. Hewstone (Eds.), Self and social identity (pp. 52-77). Malden, MA: Blackwell.] doi:10.1002/9780470998557.ch16

Kirkpatrick, L. A., Waugh, C. E., Valencia, A., \& Webster, G. D. (2002). The functional domain-specificity of self-esteem and the differential prediction of aggression. Journal of Personality and Social Psychology, 82, 756-767. https://doi.org/10.1037//0022$\underline{3514.82 .5 .756}$

Kowalski, K. C., Crocker, P. R. E., Kowalski, N. P., Chad, K. E., \& Humbert, M. L. (2003). Examining the physical self in adolescent girls over time: Further evidence against the Hierarchical Model. Journal of Sport \& Exercise Psychology, 25(1), 5-18.

Krauss, S., Orth, U., \& Robins, R. W. (2020). Family environment and self-esteem development: A longitudinal study from age 10 to 16. Journal of Personality and Social Psychology, 119(2), 457-478. https://doi.org/10.1037/pspp0000263

Kuster, F., \& Orth, U. (2013). The long-term stability of self-esteem: Its time-dependent 
decay and nonzero asymptote. Personality and Social Psychology Bulletin, 39(5), 677690. https://doi.org/10.1177/0146167213480189

Leary, M. R., Tambor, E. S., Terdal, S. K., \& Downs, D. L. (1995). Self-esteem as an interpersonal monitor: The sociometer hypothesis. Journal of Personality and Social Psychology, 68(3), 518-530. https://doi.org/10.1037/0022-3514.68.3.518

Little, T. D., Cunningham, W. A., Shahar, G., \& Widaman, K. F. (2002). To parcel or not to parcel: Exploring the question, weighing the merits. Structural Equation Modeling, 9(2), 151-173. https://doi.org/10.1207/s15328007sem0902_1

Luhmann, M., Schimmack, U., \& Eid, M. (2011). Stability and variability in the relationship between subjective well-being and income. Journal of Research in Personality, 45(2), 186-197. https://doi.org/10.1016/j.jrp.2011.01.004

MacDonald, G., \& Leary, M. R. (2012). Individual differences in self-esteem. In M. R. Leary \& J. P. Tangney (Eds.), Handbook of self and identity (2nd ed.). (pp. 354-377). Guilford Press.

Marsh, H. W., Craven, R. G., \& Martin, A. J. (2006). What is the nature of self-esteem? Unidimensional and multidimensional perspectives. In M. H. Kernis (Ed.), Self-esteem issues and answers: A sourcebook of current perspectives. (pp. 16 - 24). Psychology Press.

Marsh, H. W., Hau, K.-T., \& Grayson, D. (2005). Goodness of fit in structural equation models. In A. Maydeu-Olivares \& J. J. McArdle (Eds.), Contemporary psychometrics: A festschrift for Roderick P. McDonald. (pp. 275-340). Lawrence Erlbaum Associates Publishers.

Marsh, H. W., Smith, I. D., \& Barnes, J. (1985). Multidimensional self-concepts: Relations with sex and academic achievement. Journal of Educational Psychology, 77(5), 581596. https://doi.org/10.1037/0022-0663.77.5.581

Marsh, H. W., Smith, I. D., Barnes, J., \& Butler, S. (1983). Self-concept: Reliability, stability, 
dimensionality, validity, and the measurement of change. Journal of Educational Psychology, 75(5), 772-790. https://doi.org/10.1037/0022-0663.75.5.772

Marsh, H. W., Trautwein, U., Lüdtke, O., Köller, O., \& Baumert, J. (2006). Integration of multidimensional self-concept and core personality constructs: Construct validation and relations to well-being and achievement. Journal of Personality, 74(2), 403-456. https://doi.org/10.1111/j.1467-6494.2005.00380.x

Marsh, H. W., \& Yeung, A. S. (1998). Top-down, bottom-up, and horizontal models: The direction of causality in multidimensional, hierarchical self-concept models. Journal of Personality and Social Psychology, 75(2), 509-527. https://doi.org/10.1037/0022$\underline{3514.75 .2 .509}$

Meredith, W. (1993). Measurement invariance, factor analysis and factorial invariance. Psychometrika, 58(4), 525-543. https://doi.org/10.1007/bf02294825

Messer, B., \& Harter, S. (2012). The self-perception profile for adults: manual and questionnaires [Unpublished manuscript, University of Denver].

Muthén, L., \& Muthen, B. (1998-2019). Mplus user's guide (8th ed). Muthén \& Muthén.

Orth, U., Dapp, L. C., Erol, R. Y., Krauss, S., \& Luciano, E. C. (2021). Development of domain-specific self-evaluations: A meta-analysis of longitudinal studies. Journal of Personality and Social Psychology, 120(1), 145-172. http://dx.doi.org/10.1037/pspp0000378

Orth, U., \& Luciano, E. C. (2015). Self-esteem, narcissism, and stressful life events: Testing for selection and socialization. Journal of Personality and Social Psychology, 109(4), 707-721. https://doi.org/10.1037/pspp0000049

Orth, U. \& Robins, R. W. (2019). Development of self-esteem across the lifespan. In D. P. McAdams, R. L. Shiner, J. L. Tackett (Eds.). Handbook of personality development (pp. 328 - 344). Guilford.

Orth, U., Robins, R. W., \& Widaman, K. F. (2012). Life-span development of self-esteem and 
its effects on important life outcomes. Journal of Personality and Social Psychology, 102(6), 1271-1288. https://doi.org/10.1037/a0025558

Preckel, F., Niepel, C., Schneider, M., \& Brunner, M. (2013). Self-concept in adolescence: A longitudinal study on reciprocal effects of self-perceptions in academic and social domains. Journal of Adolescence, 36(6), 1165-1175. https://doi.org/10.1016/j.adolescence.2013.09.001

Prenoveau, J. M. (2016). Specifying and interpreting latent state-trait models with autoregression: An illustration. Structural Equation Modeling, 23(5), 731-749. https://doi.org/10.1080/10705511.2016.1186550

Pullmann, H., \& Allik, J. (2000). The Rosenberg Self-Esteem Scale: Its dimensionality, stability and personality correlates in Estonian. Personality and Individual Differences, 28(4), 701-715. https://doi.org/10.1016/S0191-8869(99)00132-4

Putnick, D. L., Hahn, C. S., Hendricks, C., \& Bornstein, M. H. (2020). Developmental stability of scholastic, social, athletic, and physical appearance self-concepts from preschool to early adulthood. Journal of Child Psychology and Psychiatry, 61(1), 95103. https://doi.org/10.1111/jepp.13107

Rentzsch, K., Erz, E., \& Schütz, A. (in press). Development of short and ultra-short forms of the Multidimensional Self-Esteem Scale: Relations to the Big Five, narcissism, and academic achievement in adults and adolescents. European Journal of Psychological Assessment.

Rentzsch, K., \& Gross, J. J. (2015). Who turns green with envy? Conceptual and empirical perspectives on dispositional envy. European Journal of Personality, 29(5), 530-547. https://doi.org/10.1002/per.2012

Rentzsch, K., \& Schröder-Abé, M. (2018). Stability and change in domain-specific selfesteem and global self-esteem. European Journal of Personality, 32(4), 353-370. https://doi.org/10.1002/per.2167 
Rentzsch, K., Wenzler, M. P., \& Schütz, A. (2016). The structure of multidimensional selfesteem across age and gender. Personality and Individual Differences, 88, 139-147. https://doi.org/10.1016/j.paid.2015.09.012

Rosenberg, M. J. (1965). Society and the adolescent self-image. Princeton University Press.

Rudolph, A., Schröder-Abé, M., \& Schütz, A. (2020). I like myself, I really do (at least right now): Development and validation of a brief and revised (German-language) version of the State Self-Esteem Scale. European Journal of Psychological Assessment, 36(1), 196-206. https://doi.org/10.1027/1015-5759/a000501

Scalas, L. F., Marsh, H. W., Nagengast, B., \& Morin, A. J. S. (2013). Latent-variable approaches to the Jamesian model of importance-weighted averages. Personality and Social Psychology Bulletin, 39(1), 100-114. https://doi.org/10.1177/0146167212465321

Schröder-Abé, M., Rudolph, A., \& Schüz, A. (2007). High implicit self-esteem is not necessarily advantagous: Discrepancies between explicit and implicit self-esteem and their relationship with anger expression and psychological health. European Journal of Personality, 21(3), 319-339. https://doi.org/10.1002/per.626

Schütz, A., Rentzsch, K., \& Sellin, I. (2016). Multidimensionale Selbstwertskala (MSWS, 2. überarb. neunorm. Aufl.) [Multidimensional Self-Esteem Scale (MSES, 2nd. ed.)]. Hogrefe.

Shavelson, R. J., \& Bolus, R. (1982). Self concept: The interplay of theory and methods. Journal of Educational Psychology, 74(1), 3-17. https://doi.org/10.1037/0022$\underline{0663.74 .1 .3}$

Shavelson, R. J., Hubner, J. J., \& Stanton, G. C. (1976). Self-concept: Validation of construct interpretations. Review of Educational Research, 46(3), 407-441. https://doi.org/10.2307/1170010

Steyer, R., Eid, M., \& Schwenkmezger, P. (1997). Modeling true intraindividual change: True 
change as a latent variable. Methods of Psychological Research, 2(1), 21-33.

Stinson, D. A., Logel, C., Zanna, M. P., Holmes, J. G., Cameron, J. J., Wood, J. V., \& Spencer, S. J. (2008). The cost of lower self-esteem: Testing a self- and social-bonds model of health. Journal of Personality and Social Psychology, 94(3), 412-428. https://doi.org/10.1037/0022-3514.94.3.412

Tesser, A., \& Martin, L. L. (2006). Self-esteem processes are central to psychological functioning and well-being. In M. H. Kernis (Ed.), Self-esteem issues and answers: A sourcebook of current perspectives. (pp. 267-271). Psychology Press.

Trautwein, U., Lüdtke, O., Köller, O., \& Baumert, J. (2006). Self-esteem, academic selfconcept, and achievement: How the learning environment moderates the dynamics of self-concept. Journal of Personality and Social Psychology, 90(2), 334-349. https://doi.org/10.1037/0022-3514.90.2.334

Trzesniewski, K. H., Donnellan, M. B., \& Robins, R. W. (2003). Stability of self-esteem across the life span. Journal of Personality and Social Psychology, 84(1), 205-220. https://doi.org/10.1037/0022-3514.84.1.205

von Soest, T., Wichstrøm, L., \& Kvalem, I. L. (2016). The development of global and domain-specific self-esteem from age 13 to 31. Journal of Personality and Social Psychology, 110(4), 592-608. https://doi.org/10.1037/pspp0000060

Wagner, J., Lang, F. R., Neyer, F. J., \& Wagner, G. G. (2014). Self-esteem across adulthood: The role of resources. European Journal of Ageing, 11(2), 109-119. https://doi.org/10.1007/s10433-013-0299-z

Wagner, J., Lüdtke, O., Jonkmann, K., \& Trautwein, U. (2013). Cherish yourself: Longitudinal patterns and conditions of self-esteem change in the transition to young adulthood. Journal of Personality and Social Psychology, 104(1), 148-163. https://doi.org/10.1037/a0029680

Wagner, J., Lüdtke, O., \& Robitzsch, A. (2019). Does personality become more stable with 
age? Disentangling state and trait effects for the big five across the life span using local structural equation modeling. Journal of Personality and Social Psychology, 116(4), 666-680. https://doi.org/10.1037/pspp0000203

Webster, G. D., Howell, J. L., \& Shepperd, J. A. (2020). Self-Esteem in 60 Seconds: The SixItem State Self-Esteem Scale (SSES-6). Assessment. https://doi.org/10.1177/1073191120958059

Wortman, J., Lucas, R. E., \& Donnellan, M. B. (2012). Stability and change in the Big Five personality domains: Evidence from a longitudinal study of Australians. Psychology and Aging, 27(4), 867-874. https://doi.org/10.1037/a0029322 


\section{Footnotes}

${ }^{1}$ Shavelson et al. (1976) used the terms "self-concept" and "self-esteem" interchangeably.

${ }^{2}$ In the present manuscript, we focused on trait self-esteem, which is typically assessed with questionnaires in which participants are asked to report how they "typically" feel about themselves. By contrast, state self-esteem is measured by asking participants to report how they feel about themselves "at the moment" (Heatherton \& Polivy, 1991; Rudolph et al., 2020; Webster et al., 2020). Contrasting trait self-esteem, which has been shown to be relatively stable, with changes manifesting across longer time periods (Orth \& Robins, 2019), state self-esteem refers to more context-based, immediate feelings of self-worth that fluctuate across the short term depending on current experiences (Kernis, 2005; Rosenberg, 1965).

${ }^{3}$ Hypotheses and analyses on the stability of global and domain-specific self-esteem were preregistered. A detailed overview of the theoretical background, hypotheses, analyses, results and discussion is provided in the Supplemental Material S2 On the Stability and Change of Global and Domain-Specific Self-Esteem (https://osf.io/h4qwt/).

${ }^{4}$ We wrote and uploaded the preregistration to the Open Science Framework on July 17, 2019 before data collection began for Wave 4. Data from Wave 1 were analyzed and reported in Rentzsch and Gross (2015) and in Rentzsch et al. (2021), and data from Waves 1 and 2 were analyzed and reported in Rentzsch and Schröder-Abé (2018). Data from Wave 3 had been collected but not analyzed prior to this preregistration, except for the data on the self-regard subscale from the Multidimensional Self-Esteem Scale (MSES) and income for a meta-analysis.

${ }^{5}$ The participant pool consisted of volunteers from the general population to participate in psychological research. This pool is subject to fluctuations, since some people no longer want to be contacted each time another study is fielded, and anyone interested can join the pool anytime. Participants of the present study were not informed that they would be 
invited to another wave of the study, since they had already given consent to be contacted each time another online survey is fielded. We believe that this is a major reason for participant dropout. Results from selection analyses are presented in Supplement S1 (https://osf.io/h4qwt/).

${ }^{6}$ Multidimensional instruments typically include a subscale for measuring global selfesteem, such as the self-regard subscale (Fleming \& Courtney, 1984), the self-esteem subscale (Marsh et al., 1985), or the global self-worth subscale (Messer \& Harter, 2012). For example, self-regard (Fleming \& Courtney, 1984) is typically assessed by using a global self-esteem subscale: Self-regard is defined in terms of favorable or unfavorable general evaluations of the self (see Fleming \& Courtney, 1984; Fleming \& Watts, 1980). Therefore, it strongly resembles Rosenberg's (1965) conceptualizations of global self-esteem. Fleming and Courtney (1984) concluded: "both are measures of the same construct" (p. 415; see also Fleming \& Watts, 1980). Empirical research has supported this notion because the two measures have been shown to be highly interrelated: The Rosenberg scale has been found to be more strongly correlated with the self-regard subscale than with any other subscale, such as performance self-esteem (Fleming \& Courtney, 1984; Schütz et al., 2016).

${ }^{7}$ We indicate specific methodological details which were not explicitly mentioned in the preregistration document.

${ }^{8}$ In contrast to the typical reporting of correlation coefficients, standardized regression coefficients based on latent regression analyses were registered for investigating rank-order stability. The analyses that were based on latent regressions revealed stronger coefficients ( $\beta \mathrm{s}$ between 0.86 and 0.91 over the course of 6 years); therefore, we decided to report the more conservative values that were based on intercorrelations. 